\title{
ESTIMATING LIQUIDITY PREMIA IN THE SPANISH GOVERNMENT SECURITIES MARKET
}

Francisco Alonso, Roberto Blanco,

Ana del Río and Alicia Sanchis

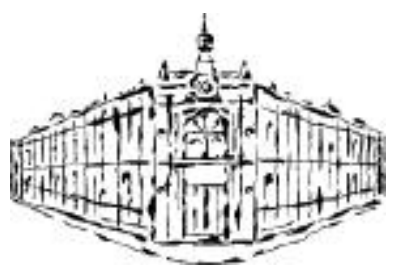

Banco de España - Servicio de Estudios

Documento de Trabajo n. ${ }^{\circ} 0017$ 


\title{
ESTIMATING LIQUIDITY PREMIA IN THE SPANISH GOVERNMENT SECURITIES MARKET*
}

\author{
Francisco Alonso \\ Roberto Blanco \\ Ana del Río \\ Alicia Sanchis
}

\footnotetext{
We wish to thank Juan Ayuso, Clemente Fernández, Víctor García-Vaquero, José Ramón Martínez, Alfredo Martínez, Jorge Martínez, Soledad Núñez, Oreste Tristani, Christian Upper and participants in the BIS' Workshop on Market Liquidity and in the seminar at Banco de España for helpful comments and suggestions.
} 


\begin{abstract}
This paper investigates the presence of liquidity premia in the relative pricing of assets traded on the Spanish government securities market. First, we propose a classification of bonds into four different categories based on their degree of liquidity. Second, we estimate liquidity premia, including liquidity parameters in the estimation of the zero-coupon yield curve. The results suggest the existence of a liquidity premium for post-benchmark bonds (both strippable and non-strippable). The size of this premium is relatively small. In the case of pre-benchmark bonds, the lack of liquidity does not seem to be priced. We also show that these pricing discrepancies are robust to the impact of taxes on bonds.
\end{abstract}

Key words: liquidity premium, bid-ask spread, yield curve, benchmark.

JEL classification: G12. 


\section{INTRODUCTION}

The liquidity of an asset is generally understood as the ease of its conversion into money ${ }^{1}$. In practice, the conversion of an asset into money involves certain costs: search costs, delays, broker's commissions, etc. The higher these costs the lower the degree of liquidity of the asset. In most financial markets there is a class of agents known as market makers whose function is to provide liquidity. These agents are ready to buy and sell securities up to a maximum amount and make their profit on the difference between the bid and ask prices. The latter are the prices at which the other market participants can execute surely and immediately sell and buy transactions, respectively. As a consequence, the bid-ask spread reflects the cost incurred by a typical investor to unwind an asset position, which is part of the cost of converting an asset into money. This is why the bid-ask spread is one of the most widely used measures of liquidity.

According to market microstructure models, the bid-ask spread may reflect three different costs faced by market makers: asymmetric information costs, inventory costs, and orderprocessing costs. However, as Gravelle (BIS, 1999) points out, asymmetric information costs should not be very significant in the case of government securities (GS). This implies that liquidity in GS markets should be closely linked to the market-makers' inventory risk and order-processing costs which ultimately depend on the level of risk of the asset (duration) and the frequency with which a transaction will be executed (turnover). Sometimes liquidity is measured by indicators of market activity (turnover, turnover ratio, benchmark status, age).

Because investors value asset liquidity we can expect liquidity and differences in liquidity to be priced. In other words, investors may require a liquidity premium for holding illiquid assets in order to compensate them for bearing higher transaction costs. In the literature, there are some papers that test for the existence of liquidity premia in securities markets. The bulk of this literature focuses on equity markets ${ }^{2}$, whereas there are only a few papers that focus on debt markets, most of them using US market data.

Papers that test for the existence of a liquidity premium in GS markets have followed a number of approaches. For example, in Amihud and Mendelson (1991), Kamara (1994) and Garbade (1996) the liquidity premium is only estimated for short-term US Treasuries. They compare the yield of notes with that of bills with the same term to maturity. Since both instruments are identical, except for the fact that notes are more actively traded, yield differences are attributed to differences in liquidity. The liquidity premia in these papers are

\footnotetext{
${ }^{1}$ See Market liquidity: Research Findings and Selected Policy Implications in BIS (1999) for the various dimensions of liquidity.

${ }^{2}$ See, for example Amihud and Mendelson (1986,1989).
} 
found to be high and significant. Elton and Green (1998) use volume as a proxy for liquidity and introduce it as an explanatory variable when fitting a zero-coupon curve to the US market. They find that the coefficient of this variable is significant for most of the days considered, although the implied liquidity premium is very small. Warga (1992) proxies liquidity by indicating whether or not an issue is on-the-run (the most recently issued security of a particular maturity). He compares the ex-post monthly excess return over the 30-day Treasury bill rate for two series of constant duration portfolios made up of securities traded on the US market, one containing on-the-run bonds and the other containing the other available bonds. Warga (1992) finds that portfolios containing on-the-run bonds exhibit a lower return and interprets this as evidence of a liquidity premium. In other papers, like Shen and Starr (1998), liquidity is proxied by the bid-ask spread. In that paper the term premium, proxied by the excess ex-post returns of the six-month US T-bill over the 3-month bill, is estimated and it is found that the bid-ask spread accounts for a substantial portion of this premium.

The estimation of liquidity premia in GS markets is important because, among other reasons, it might improve the information content of prices. For example, the existence of liquidity premia may distort the information extracted from the estimated term structure or the estimates of implied inflation expectations obtained by comparing fixed-coupon and inflation linked bonds.

Against this background, the main goal of this paper is to investigate whether there is a liquidity premium in the relative pricing of assets traded on the Spanish GS market. To do this, we first characterise the relative liquidity of bonds. The strippability of the asset and its benchmark status appear to be two relevant determinants of securities' liquidity within each maturity zone. Given this property, we consider four categories of bonds that take into account these elements. The categories are non-strippable bonds and pre-benchmark (bonds that will have the benchmark status in the future), benchmark and post-benchmark (bonds that had the benchmark status in the past) strippable bonds. We find that there are important liquidity differences among these categories of bonds according to different measures of liquidity based on activity measures and bid-ask spreads. Benchmark bonds are the most liquid, followed by strippable non-benchmark bonds. And finally non-strippable bonds appear to be very illiquid.

In the second part of the paper we estimate relative liquidity premia. A traditional approach is to calculate the yield spread between non-benchmark and benchmark bonds. However, this estimation of the liquidity premia does not control for risk and tax factors derived from the different cash flow structures of bonds. Our methodology follows that of Elton and Green (1998) which is based on the estimation of the term structure of interest rates. This approach affords us better control over effects related to the cash-flow structure of bonds. Specifically, we incorporate liquidity effects in the estimation of the zero-coupon yield curve 
introducing dummy variables for the different categories of bonds. The results suggest the existence of a liquidity premium for post-benchmark bonds (both strippable and nonstrippable). The size of this premium is relatively small. In the case of pre-benchmark bonds, the lack of liquidity does not seem to be priced. In fact, in some periods we even find evidence of a negative premium over benchmark issues for pre-benchmark bonds. We also show that these pricing discrepancies are robust to the impact of taxes on bonds. Thus, these results point to the existence of a liquidity premium in the relative pricing of bonds traded on the Spanish GS market, although its size seems relatively small.

The remainder of the paper is organised as follows. Section 2 describes the structure of the Spanish GS market. Section 3 describes the data. Section 4 proposes a classification of bonds which tries to identify bonds with a different degree of liquidity. Section 5 estimates liquidity premia. And, finally, Section 6 summarises the main conclusions.

\section{STRUCTURE OF THE SPANISH GOVERNMENT SECURITIES MARKET}

Two types of instrument are issued by the Spanish Treasury: Letras del Tesoro (Treasury bills), which are short-term securities issued at a discount, and Bonos y Obligaciones del Estado (government bonds) which are medium and long-term securities with annual coupon payments. Both types of instruments are represented by book entries and issued via regular competitive auctions. Bills are issued at 6-, 12- and 18-month maturities, whereas bonds are issued at 3-, 5-, 10-, 15- and 30-year maturities. Auctions take place on a monthly basis, except for 15-year and 30-year issues, which are auctioned every two months, and 12- and 18-month issues, which are auctioned fortnightly. In the case of medium and long-term securities, issues are reopened over several consecutive auctions until the outstanding amount reaches a certain level. The securities allocated at such auctions have identical nominal coupon and interest payment and redemption dates.

Since July 1997, the Spanish Treasury has been issuing strippable bonds. They enjoy a more favourable tax treatment for payers of the corporate income tax, because the latter are not subject to withholding tax on coupon payments. These securities can be stripped during their life into $n+1$ zero-coupon assets, where $n$ stands for the number of remaining coupon payments, arising from the cash flow generated by the bond's coupons and the principal. The stripping process is conducted by a type of market participant known as market makers, who assume a number of commitments subject to annual review. They are also allowed to perform the reverse process (reconstitution). All outstanding bonds issued before July 1997 are non-strippable and do not enjoy the favourable tax treatment of strippable bonds. 
Secondary market trades are conducted through three systems, the first two being reserved for market members, while the third is for transactions between market members and their clients. In the first system (known as the "blind market") trading is electronically conducted without knowledge of the counterparty's identity. Only those market members who comply with certain requirements and assume a number of commitments can participate in this market segment. For instance, they are obliged to quote during at least $60 \%$ of the time of each session the five issues of bonds with benchmark status, subject to a maximum bid-ask spread. Blind market trades can only be outright transactions, whether spot or forward.

The second trading system (known as the "second tier") channels all the remaining transactions between market members. Trading is conducted directly between traders or through brokers. Some brokers post indicative bid and ask prices on electronic market information systems such as Reuters and Bloomberg. In this market segment, participants can trade outright (in spot or forward transactions) or enter into repos. Two types of repo transaction are allowed: ordinary repos and blocked repos, the difference being that under the second type the buyer cannot transact freely with the securities purchased, regardless of the agreed buy-back date.

Clearing and settlement of GS transactions is carried out by the Central de Anotaciones en Cuenta (Book-Entry System). Each market member holds an account in this system. Individuals or institutions who are not members have to channel transactions through a Managing Institution. The procedure used is one of delivery versus payment and transactions are settled three business days later.

In addition to the secondary market, there is a futures and options market (MEFF RF) where the underlying assets are Spanish GS. At present traded contracts include only 10-year futures and options.

Table 1 provides 1999 turnover figures for the different market segments and for the different types of transaction on the Spanish GS market. Repos are the type of transaction with the highest activity, which is mainly concentrated in the very short-term (mainly overnight), followed by outright spot purchases. By contrast, trading activity through forward, futures, and options transactions, is more limited.

Table 2 gives a breakdown of the holders of Spanish GS at end-1999. Financial institutions own a very large proportion of the outstanding amount $(61.2 \%$ for bonds and $91.3 \%$ for bills). Non-residents also have a significant share of the market in the case of bonds $(32 \%)$. By contrast, the share of non-financial corporations and households is very low. 


\section{DATA}

In this paper we use daily data on prices (quoted and traded), outstanding amounts, and trading activity (trading volume and number of trades) for the Spanish GS market from January 1999 to April 2000. This information is compiled for 34 bonds $^{3}, 24$ of them being outstanding throughout the sample period (see Table 3 for a description of the issues). For the short-term, the data refer to Treasury bills and repo transactions.

The price data include the following:

i) Daily mean prices traded in the blind and second-tier markets. This information was provided by the Central de Anotaciones of the Banco de España

ii) Daily quoted bid and ask prices obtained from two sources:

a) Reuters-BDE: since August 1998 the Banco de España Research Department has been building a database from prices posted by Reuters at 2 p.m. It includes best quoted bid and ask prices for long and short-term issues; and bid and ask rates for repo transactions. Daily bid and ask prices are calculated using the quotations of four brokers: three ${ }^{4}$ of them are pre-determined and the fourth is the one who traded most recently. From these quotations, the highest bid and the lowest ask prices are selected for each issue. If the bid price is higher than the ask ${ }^{5}$, then prices are sequentially removed until a non-negative spread is obtained.

b) Bloomberg: this agency provides daily quoted prices calculated as the average bid and ask quotations at the close (determined by Bloomberg to be about 5 p.m.). In this case, by construction, the bid-ask spread is always positive. Bloomberg also provides bid and ask rates for a wide range of repo transactions.

In this paper we will use quoted prices instead of traded prices to test for liquidity effects. This decision is driven by the methodology we use, consisting of the daily estimation of a zero-coupon yield curve. The non-contemporaneity?? problem of traded prices together with the lack of prices for bonds that are not traded on a particular day would lead to some important errors in the estimation. However, it has to be stressed that quoted prices are not firm but indicative, and therefore they may not reflect actual prices. For that reason we also perform a robust test on the accuracy of these prices by comparing them to actual traded

\footnotetext{
${ }^{3}$ Strips are not included. The percentage of stripped bonds is very low in the Spanish market.

${ }^{4}$ Four in the case of short-term instruments.

${ }^{5}$ In the information provided by Reuters it is not uncommon to find negative bid-ask spreads, possibly due to the lack of contemporaneity in quotations.
} 
prices. Regarding the information on bid-ask spreads, it is worth noting that we have two indicators computed using two different methodologies. On one hand, the Reuters-BDE spread is the best proxy for market spread, but it employs non-contemporaneous quotations that may introduce noise and may bias downwards the size of the spread. On the other hand, the Bloomberg spread cannot be interpreted as the market spread, but its main advantage is that it reduces non-contemporaneity problems due to the fact that quotes are averaged.

Finally, trading activity (number of trades and trading volume) is provided by the Central de Anotaciones of the Banco de España and refers only to transactions between market members, in both the blind and the second-tier market.

\section{CLASSIFYING BONDS BY THEIR RELATIVE DEGREE OF LIQUIDITY}

\subsection{A classification of bonds according to their life cycle and tax treatment}

In this section we propose a classification of bonds that tries to identify a number of groups of bonds with different degrees of liquidity. It is important to stress that the approach we follow in this paper of classifying bonds by their relative liquidity is not intended to compare liquidity across different maturity zones but within them. This decision is justified by the methodology we use in the next section to estimate liquidity premia, which consists of fitting a zero-coupon yield curve. With this methodology it would be very difficult to separate term and liquidity effects if we used a classification of liquidity across different maturities.

Our classification takes into account two elements of an issue: its stage of the life cycle and its strippability (whether or not the issue is strippable). We consider the stage of life because, in general, trading activity and, consequently, liquidity is related to this. It is well known that in GS markets trading activity tends to be concentrated in a small group of securities known as benchmark issues. The prices of these instruments are used to extract information for macroeconomic analysis and pricing purposes. In the Spanish GS market there are five benchmark issues corresponding to 3-, 5-, 10-, 15- and 30-year maturities. Since all issued bonds become benchmark issues, the life cycle of bonds consists of three stages. In the first stage, the bond is initially issued and its outstanding volume is relatively small, and hence its trading activity is very low and it does not have benchmark status. Bonds in this stage will hereinafter be referred to as pre-benchmark issues. New fungible auctions increase the outstanding amount, and trading activity also increases until benchmark status is achieved and the issue becomes the most liquid one for a particular maturity. Finally, in the third stage, the bond is replaced by a new benchmark and its activity begins to decrease. Bonds in this stage will be referred to as post-benchmark issues. 
More specifically, our classification consists of four categories, namely: pre-benchmark, benchmark, post-benchmark and non-strippable issues. The first three categories are only made up of strippable bonds, whereas the last category includes all non-strippable bonds. We have decided to group all non-strippable bonds in one specific category for the following two reasons. First, in our sample, all non-strippable bonds are at a very advanced third stage of their life cycle, therefore they are very illiquid. And, second, they are subject to a less favourable tax treatment that could be reflected in a tax premium.

Over our sample period there was no official classification of benchmark issues in Spain. As a consequence, the identification of the benchmark issue may be difficult during transition periods. The criterion we use in this paper considers that a new bond becomes the benchmark issue when it has been traded more than the old benchmark for at least three consecutive days. Table 4 gives the dates on which a benchmark bond changes according to this criterion, and compares them with those reported by Reuters and Bloomberg. It can be observed that dates do not coincide for the different criteria, but differences between them rarely exceed one month.

Figure 1 shows the life cycle for all the strippable 10-year bonds of our sample. Over this period there are two changes of benchmark, one in February 1999 when the $5.15 \%$ bond becomes the new benchmark, and the other in October 1999, when the most recently issued bond (4\% with maturity at $31 / 1 / 10)$ acquires benchmark status. This figure displays the evolution of trading activity, outstanding volume and bid-ask spread. It can be seen that the life cycle in trading activity appears also to be incorporated in the evolution of bid-ask spreads, suggesting a very different degree of liquidity of bonds depending on the stage of life they are at.

Table 5 gives a descriptive analysis of previously defined bond categories over our sample period. Panel A shows the average number of issues for each category in the sample. The non-strippable category is the one with the highest number of issues (18.7 on average). At the other extreme, only 2.6 bonds belong to the pre-benchmark category on average. The post-benchmark category includes an average of 4.4 issues. However, the number of bonds in this category increases throughout the sample period to reach 9 at the end.

In panel $\mathrm{C}$ of Table 5 it can be seen that benchmark issues account, on average, for almost $53 \%$ of the daily traded volume. Regarding non-strippable bonds, despite the high number of issues, they account for just $7 \%$ of daily traded volume (see panel C). Finally, the remaining $40 \%$ of the traded volume corresponds to strippable non-benchmark bonds -of which pre-benchmark issues account for $15 \%$ and post-benchmark issues for $25 \%$.

Looking at trading activity by maturity, a high concentration around the 10-year zone is observed, with approximately $33 \%$ of the total market activity. The 3- and 5-year maturities 
account for approximately $25 \%$ and $23 \%$ respectively. And finally, the zones of 15 - and 30 year residual maturity have the lowest activity, with approximately $5 \%$ and $3 \%$ of total market activity respectively.

Regarding outstanding volume, panel B of Table 5 shows a very different distribution. In particular, a high concentration (more than 50\%) is observed in the 0-6 years zone.

\subsection{Is this classification useful to identify groups of bonds with a different degree of liquidity?}

We now show to what extent the four categories we propose are useful to identify groups of bonds with a different degree of liquidity. To do this we compute some liquidity measures for the different categories of bonds.

Table 6 reports various measures of liquidity, all based on trading activity, with a breakdown by bond category and maturity. These measures are the number of trades, trading volume and turnover ratio. All these indicators are computed per bond and, therefore, can be interpreted as liquidity measures. A feature shared by all the liquidity measures of Table 6 is the remarkable differences in liquidity between the various categories considered.

When comparing liquidity within each maturity zone, benchmark issues are the bonds with the greatest liquidity, followed by strippable non-benchmark bonds (both pre-benchmark ${ }^{6}$ and post-benchmark). Finally, non-strippable bonds are notable for their very scarce trading activity.

When comparing liquidity among maturity zones the most liquid bonds are those with a residual maturity between 3 and 10 years. In this regard, it is worth noting that strippable non-benchmark bonds are sometimes even more liquid than 15 and 30-year benchmark issues.

Figure 2 displays the bid-ask spread $^{7}$ as a function of the duration for the different categories of bonds. This indicator is used as an additional measure of liquidity. A similar pattern to that reported for trading activity also appears here when comparing the liquidity of bonds within each maturity zone (proxied by duration), although now pre-benchmark issues appear to be more similar, in terms of liquidity, to non-strippable bonds than to postbenchmark strippable issues.

\footnotetext{
${ }^{6}$ In fact, in the case of the turnover ratio, no significant differences are observed between pre-benchmark and benchmark issues.

${ }^{7}$ For this analysis we use the Reuters-BDE database because it provides a spread measure more closely linked to the concept of market spread (see Section 3 for a description of this database and a comparison with the Bloomberg data).
} 
However, note that trading activity and the bid-ask spread would provide a very different ranking of bonds by liquidity if we did not control for time to maturity or duration. As Figure 2 illustrates, the bid-ask spread is positively correlated with time to maturity. This effect clearly dominates the previously reported pattern (benchmark status of the bond). This relationship between spread and time to maturity, which has also been identified in other GS markets ${ }^{8}$, can be explained theoretically by the market makers' inventory risk and order processing costs, which ultimately depend on the level of risk of the asset proxied by time to maturity. Accordingly, a ranking of bonds using the bid-ask spread would classify short-term securities as the most liquid and long-term issues as relatively illiquid. Conversely, a ranking of bonds by the liquidity measures of Table 6 would classify the 10-year bonds as the most liquid issues.

It is worth noting that our classification of bonds can be justified either by the bid-ask spread or by the trading activity measures because, as was mentioned before, we do not intend to compare liquidity across different maturity zones but within them.

Three conclusions may be drawn from the previous analysis. First, the benchmark status and strippability of bonds are two relevant determinants of the liquidity differences within a maturity zone for the bonds in our sample. Second, the four categories we consider seem useful to identify groups of bonds with different degrees of liquidity. And, finally there appear to be big differences in liquidity between bonds, so that it makes sense to test for the existence of a liquidity premium. This is the aim of the next section of the paper.

\section{ESTIMATING LIQUIDITY PREMIA}

\subsection{Preliminary analysis}

Our aim in this second part of the paper is to find out if differences in liquidity are priced in the Spanish GS market. One simple approach is to approximate the liquidity premium by the yield spread between non-benchmark and benchmark bonds. Applying this measure to the 3,5, 10 and 15-year bonds of our sample always gives a negative figure, suggesting the existence of negative liquidity premia. However, it has to be taken into account that some factors may bias this measure. Differences in coupons between bonds imply different risk and tax burdens that may make the investor demand different yields to maturity for other reasons not related to liquidity effects. The main difficulty when identifying the liquidity premium is the separation of the factors explaining differences in yields to maturity. With

\footnotetext{
${ }^{8}$ BIS (1999) compares bid-ask spreads for "on-the-run" and "off-the-run" issues for Canada, Italy, Japan, UK and US. In all cases they find the same results as ours, except for Japan, where the liquidity of on-the-run 10-year bonds makes their spread narrower than the one for "on-the-run" 5-year bonds. (See Table 3 of the document Market Liquidity: Research Findings and Selected Policy Implications)
} 
this in mind, our proposal is based on the estimation of the term structure of interest rates, because this allows us to control any effect associated with differences in maturity and cash flows. This approach is similar to that followed by Elton and Green (1998).

According to the analysis developed in Section 4, we distinguish four types of bonds in relation to their life cycle and tax treatment: non-strippable bonds and pre-benchmark, postbenchmark and benchmark strippable bonds.

As a preliminary analysis of the existence of liquidity premia we estimate a zero-coupon yield curve using the Svensson model ${ }^{9,10}$ and analyse yield errors for bonds. We find a very interesting pattern. Figure 3 shows the estimation for a representative day of the sample, (29/3/99) and Table 7 reports average yield errors for each bond in our sample, distinguishing its classification over the sample period. The first thing we observe is that most non-strippable bonds appear to have on average positive yield errors, i.e. they are located above the estimated yield curve. The second point to be stressed is the tendency of pre-benchmark bonds to exhibit a lower yield error than benchmark bonds. Finally, the yield error of post-benchmark bonds lies between the yield errors of benchmark and nonstrippable bonds. These results provide preliminary evidence of a positive premium for postbenchmark and non-strippable bonds over benchmark issues. The next section tries to estimate them using a more formal approach.

\subsection{Estimating the yield curve incorporating liquidity effects}

Previous results indicate that the estimation of the yield curve for the Spanish GS market may be improved if we introduce liquidity and withholding-tax effects. Our approach consists of estimating the term structure of interest rates using the Svensson model, and introducing dummy variables to capture these effects. These variables allow us to classify securities according to their degree of liquidity and their tax treatment and to estimate liquidity premia. Elton and Green (1998) follow a similar procedure ${ }^{11}$ but they introduce volume as a measure of liquidity. We prefer to use qualitative instead of quantitative variables for the following reasons. First, there is no consensus on what is the best direct measure of liquidity. Second, the traditional measures of liquidity (volume and bid-ask spread) are very noisy at a daily level, i.e. they are much more volatile than the expected pattern of liquidity. And, finally, the relationship between liquidity measures and liquidity premia may not be linear.

\footnotetext{
${ }^{9}$ See Annex 1 for a description of the Svensson model.

${ }^{10}$ From now on, all the estimation results are obtained using the Bloomberg dataset. When we use the Reuters-BDE dataset we obtain similar results.

${ }^{11}$ They use non-linear least squares to fit a cubic spline to the after-tax cash flows of bonds.
} 
The instantaneous forward rate of term $m$ is modelled in the following way:

$$
\varphi_{m}=\beta_{0}+\beta_{1} e^{-\frac{m}{\tau_{1}}}+\beta_{2} \frac{m}{\tau_{1}} e^{-\frac{m}{\tau_{1}}}+\beta_{3} \frac{m}{\tau_{2}} e^{-\frac{m}{\tau_{2}}}+\gamma_{0} \text { PREBENCH }+\gamma_{1} \text { POSTBENCH }+\gamma_{2} \text { NONSTRIP }
$$

where PREBENCH, POSTBENCH and NONSTRIPare dummy variables which take the value 1 for pre-benchmark, post-benchmark and non-strippable bonds respectively. Parameters for dummy variables must be interpreted in relation to the remaining instruments $(3,5,10,15$ and 30-year benchmark bonds and short-term securities).

Parameters $\gamma_{0}, \gamma_{1}$ and $\gamma_{2}$ capture the excess yield demanded on pre-benchmark, postbenchmark and non-strippable bonds respectively. Parameters $\gamma_{0}$ and $\gamma_{1}$ can be directly interpreted as liquidity premia since the tax treatment is the same for all strippable issues. Conversely, parameter $\gamma_{2}$ may incorporate a tax premium in addition to a liquidity premium due to the relatively less favourable tax treatment of non-strippable bonds. The interpretation of the remaining parameters is the standard one in the Svensson model.

Once we have modelled the instantaneous forward rate including withholding-tax and liquidity effects, we estimate the parameter vector $\beta=\left(\beta_{0}, \beta_{1}, \beta_{2}, \tau_{1}, \beta_{3}, \tau_{2}, \gamma_{0}, \gamma_{1}, \gamma_{2}\right)$ for each day $t$ as

$$
\hat{\beta}=\arg \min \sum_{i=1}^{N}\left[\frac{p_{t i}-p_{t i}(\beta)}{p_{t i}}\right]^{2}
$$

where $p_{t i}$ is the actual price ${ }^{12}$ of bond $i$ at time $t, p_{t i}(\beta)$ is the theoretical price obtained from previous specification of the instantaneous forward rate, and $\mathrm{N}$ is the number of securities considered in the estimation. We minimise price errors instead of yield errors to obtain a better fit for the maturities we are most interested in -i.e. medium and long-term.

We estimate the model with liquidity and withholding-tax effects (model 2) and compare it with a model without these effects where parameters $\gamma_{0}, \gamma_{1}, \gamma_{2}$ are restricted to zero (model 1). These models are estimated daily from January 1999 to April 2000 . Over the period $4 / 1 / 99$ to $30 / 9 / 99$ the Svensson model does not improve on the Nelson-Siegel model ${ }^{13}$ and consequently, we estimate the latter model for this period. Table $8^{14}$ reports a descriptive

\footnotetext{
${ }^{12}$ We use the mid-point between the quoted bid and ask prices. For short-term we use repo and bill rates.

${ }^{13}$ This model is a particular case of the Svensson model, where the instantaneous forward rate is modelled with just one hump, i.e. $\beta_{3}$ and $\tau_{2}$ are set to zero and one respectively.

${ }^{14}$ We concentrate on the interpretation of parameters $\gamma_{0}, \gamma_{1}, \gamma_{2}$, which will be reported in different tables. The remaining parameters of the Svensson and Nelson-Siegel model are presented in Table 12 for all the models estimated in the paper.
} 
analysis of the parameters estimated for dummy variables, the root mean square error (RMSE), and the reduction in the RMSE with respect to model 1.

Model 2 reduces the RMSE by $63 \%$ on average. The parameter of post-benchmark and non-strippable bonds is positive and significant for most days of the sample, which may be interpreted as evidence of the existence of liquidity premia. By contrast, the parameter of pre-benchmark bonds turns out to be negative on average, suggesting the existence of a negative premium for these bonds over benchmark issues. However, some care must be taken in the interpretation of this parameter. It is negatively significant for just $55 \%$ of the sample period, and in some periods there is just one bond included in this category. The conclusion drawn from the analysis of this parameter is that pre-benchmark bonds do not seem to include any positive liquidity premium in spite of their low liquidity in terms of trading activity and bid-ask spreads. This result may possibly be explained by the forwardlooking behaviour of investors. It is costly to trade these securities, but investors do not demand a higher yield because, in the future, these costs will be much lower when the bond acquires benchmark status. In addition, the limited supply of these issues may help to sustain their price.

Given that pre-benchmark bonds do not appear to have a positive liquidity premium over benchmark issues we proceed to group pre-benchmark and benchmark bonds into the same category. Model 3 includes only two dummy variables to capture liquidity differences, one for post-benchmark and the other for non-strippable bonds. The reduction of RMSE with respect to model 1 continues to be very high (50\%). Non-strippable bonds appear to have a premium of 8 basis points on average, ranging from 5.1 to 11.7 basis points. This parameter is statistically significant for the whole sample period. Post-benchmark bonds also appear to incorporate a premium. It takes the value of 5.2 basis points on average, but in this case there are some periods where the parameter of this variable is not positive and statistically significant. Figure 4 shows the evolution of estimated parameters $\gamma_{1}, \gamma_{2}$. Shaded areas indicate that $\gamma_{1}$ is not statistically significant. These areas coincide with periods in which the benchmark issues change. During these periods frontiers between strippable categories are blurred making it difficult to interpret parameter $\gamma_{1}$.

The small number of issues in the post-benchmark category may raise some doubts about the accuracy of the estimation of parameter $\gamma_{1}$. However, this problem does not seem to be too serious if we take into account that parameter $\gamma_{1}$ is significant every day in periods in which the liquidity categories of bonds are sufficiently differentiated.

Summing up, the results of this section suggest the existence of a positive liquidity premium for post-benchmark issues over benchmark bonds, although its size is very small - similar to that found by Elton and Green (1998) in the US market. Conversely, the lack of liquidity of pre-benchmark issues does not seem to be priced and, even a negative premium over 
benchmark issues is found in some periods. Finally, there is clear evidence of a positive premium for non-strippable bonds over the whole sample period. However, as noted before, this premium cannot be interpreted directly as a liquidity premium since the excess yield demanded on non-strippable bonds may also include a withholding-tax premium. In the next section we try to separate these two components.

\subsection{Separation of withholding-tax and liquidity effects for non-strippable bonds.}

Previous results show strong evidence of a premium for non-strippable bonds that, initially, may be due to liquidity or withholding-tax effects. In order to isolate the liquidity effects we re-estimate Model 3 modifying the cash flows of non-strippable bonds (Model 4) by introducing withholding-tax effects. To do this, we consider three different tax scenarios. The main results are summarised in Table 9.

We start with the extreme case in which withholding tax is fully set off against the annual payment of corporate income tax. We include the cost of withholding tax, which reduces the amount of coupon payments by $18 \%$ (the withholding tax rate during the sample period) and a new cash flow stream, corresponding to the compensation for the withholding tax, at the date of the annual tax payment. Under this tax scenario, the estimation results show no evidence of a liquidity premium for non-strippable bonds. On average, we obtain a negative premium very close to zero. However in only $34 \%$ of the sample period is this negative premium statistically significant, while in $17 \%$ of the sample period the liquidity premium takes a positive value. These results would imply that the excess return found for nonstrippable bonds is mainly explained by their tax cost. However, this tax scenario is difficult to uphold for various reasons. First, most investment institutions set off withholding tax against quarterly payments of corporate income tax rather than annual payments. Second, withholding-tax costs may be reduced through coupon-washing transactions ${ }^{15}$. This leads us to consider two alternative and more realistic tax scenarios.

Spanish corporate income tax requires quarterly payments to be made based on estimated profits during each quarter. These quarterly payments are then reconsidered in the annual tax return. In practice, most investment institutions are subject to these quarterly payments and therefore the withholding tax is set off against the next quarterly payment instead of in the annual tax return. This leads us to consider a more realistic second tax scenario in which the withholding tax is set off against the next quarterly payment. This tax scenario is still an extreme case in the sense that the cost of withholding tax might be reduced through coupon-washing transactions. The results of the estimations show an average liquidity

\footnotetext{
${ }^{15}$ These transactions consist of selling non-strippable bonds to non-resident investors, who are not subject to withholding tax, before the date of the coupon, and buying them back again after that date.
} 
premium for non-strippable bonds of 6.8 basis points that proves to be statistically significant for the whole sample period. Therefore, in this case, the cost of withholding tax is small, around 1.2 basis points considering the results of Model 3 . The liquidity premium for post-benchmark bonds does not change significantly, and its size is still smaller than the one for non-strippable bonds. This fact could be explained by the lower degree of liquidity of the latter bonds.

Finally, we consider a third tax scenario in which the withholding-tax cost of the first tax scenario is reduced through coupon-washing transactions. We suppose that resident and non-resident investors share the profit on this transaction equally. This profit is the cost saved by avoiding the withholding tax. Under this scenario we again find evidence of a positive liquidity premium for non-strippable bonds. It takes the value of 3.6 basis points on average. Therefore under this scenario the cost of withholding tax is 4.2 basis points with respect to Model 3 . This liquidity premium is statistically significant in $75 \%$ of the sample period. The liquidity premium for post-benchmark bonds does not change significantly, and it is now larger in size than the one for non-strippable bonds.

To sum up, the separation of withholding tax and liquidity effects for non-strippable bonds requires assumptions to be made. Excluding the most extreme and unrealistic case, we have found that the previously reported premia for non-strippable bonds mostly reflect a liquidity premium, whose size ranges between 6.8 and 3.6 basis points. The liquidity premium for post-benchmark bonds does not change significantly and, on average, takes the value of 5.2 basis points. Here, it is worth noting that differences in liquidity between post-benchmark and non-strippable bonds do not seem to imply significant differences in their liquidity premium. This result might suggest that there is no linear relationship between the liquidity premium and trading activity.

\subsection{Robustness to tax effects}

The above results may be sensitive to the inclusion of general tax effects in the estimation of the zero-coupon yield curve. That is, they may be affected by the estimation of a pre-tax instead of a post-tax yield curve. It is very difficult to estimate a post-tax yield curve, because tax treatment is very different across investors. In this section we estimate a posttax yield curve considering the tax treatment for Spanish corporations, which hold two thirds of the outstanding volume of bonds (see Table 2).

The theoretical price is expressed as the present value of after-tax cash flows, with a tax rate of $35 \%$ imposed on both interest payments and capital gains. Capital gains or losses at the redemption date are distributed over the life of the bond using a constant yield method, and assuming that the bond is held until maturity. 
Table 10 shows the main results of the re-estimation of Model 3 using after-tax flows (Model $5)$. It can be seen that in this new model the sign and significance of estimated premia remain unchanged, but their absolute size is reduced by around $35 \%$. The parameters that capture the asymptotic value of the instantaneous forward rate $\left(\beta_{0}=\varphi_{\infty}\right)$ and the instantaneous forward rate for an infinitely small term to maturity $\left(\beta_{0}+\beta_{1}=\varphi_{0}\right)$ are also reduced by around $35 \%$. Consequently, the liquidity premia expressed as a percentage of these interest rates remain almost unchanged (see Table 11). These results indicate that previously estimated relative liquidity premia are robust to tax effects.

Finally, it is interesting to see that the model with taxes further reduces the RMSE. On average the reduction over the basic model is $76 \%$, which compares with the $50 \%$ reduction of the model with two dummies but without taxes (model 3). This result suggests the relevance of introducing tax effects when fitting zero-coupon yield curves.

\subsection{Impact of liquidity premia on the estimated yield curve}

In this subsection we study the impact of the introduction of liquidity effects on the estimated zero-coupon yield curve. To do this we compare the estimated parameters for the different models we have considered in subsections 5.2 to 5.4 .

Table 12 reports the mean and the standard deviation of the basic parameters of the term structure $^{16}$. The mean of the parameters' estimates for the models that introduce liquidity effects without taxes (Models 2 to 4 ) are very close to those of the basic model (Model 1). This is not a surprising result given the relatively small liquidity premia we have found. Conversely, when taxes are introduced (Model 5) some parameters change significantly. $\beta_{0}$ and $\beta_{1}$ are now around $35 \%$ (the tax rate) below the estimated level for Model 3, whereas the changes in the other parameters are less dramatic. These changes imply that after-tax zero-coupon rates are around $35 \%$ below before-tax rates.

Figure 5 depicts the zero-coupon yield curve at 29/3/99 for two of the models we have estimated, using the Nelson-Siegel approach. The models we consider in this figure are the basic model (Model 1) and the model that introduces dummy variables for both postbenchmark and non-strippable bonds (Model 3). The yield curve of the model that accounts for liquidity (Model 3) stands slightly above (with a maximum difference of 9 basis points) that of the basic model for short-term maturities and slightly below it (with a maximum difference of 12 basis points) for medium-term horizons. For long-term maturities both models display very similar rates.

\footnotetext{
${ }^{16}$ From 4/01/99 to 30/9/99 we estimate the Nelson-Siegel model, and from 1/10/99 to 14/4/00 the Svensson model.
} 
Figure 6 shows the estimated 1-year forward curves implied by the yield curves depicted in Figure 5. Estimated forward rates for horizons shorter than 6 years are slightly lower for the model that accounts for liquidity effects, whereas the opposite is the case for longer horizons.

Figures 7 and 8 are the same as Figures 5 and 6, except for the fact that they are estimated at $31 / 3 / 00$ using the Svensson model. In this case, the zero-coupon rates are lower for the model that introduces liquidity effects in comparison with the basic model, for all horizons. It is worth noting that for the medium and long-term horizons the difference between the two curves is smaller than that found with Figure 5. This is not surprising given the reduction in the estimated liquidity premia in the second half of the sample period.

The introduction of liquidity effects has allowed us to identify liquidity premia and to reduce the error in the estimation of the zero-coupon yield curve. However, the implications for the information content of the estimated yield curve are not very important. This is an expected result given the small size of the estimated liquidity premium.

\subsection{Biases in quoted prices}

The results of the previous analysis have been derived from the quoted prices posted by brokers in Bloomberg. We know that these prices are not firm, but merely informative and, consequently, we do not know how accurate they are. The existence of a bias in quoted prices may have an impact on the liquidity premia we have estimated. In this subsection we study the existence of biases in quoted prices in comparison with traded prices and derive conclusions on their impact on the estimated liquidity premia. To do this, for each day and security we compute the difference in yield between the mean traded price and the midquoted price. Table 13 shows the average of these yield differences for each security, distinguishing its classification over the sample period in the four categories we have considered in this paper (pre-benchmark, benchmark, post-benchmark and non-strippable).

Three important features emerge from Table 13. First, average yield differences are very small for almost all securities ${ }^{17}$ (between 0 and 2.3 basis points), most of them being not significantly different from zero. Second, yield differences tend to be positive for most bonds (those figures statistically different from zero are all positive). Third, yield differences tend to be higher for pre-benchmark and non-strippable bonds.

These results suggest the existence of a small negative bias in quoted prices in comparison with traded prices, which seems to be more important for pre-benchmark and non-strippable

\footnotetext{
${ }^{17}$ The only exception being those bonds that mature within the sample period. The low duration of these bonds implies that small differences in quoted and traded prices translate into significant discrepancies in terms of yield to maturity.
} 
issues. This would mean that there is a negative bias in the liquidity premia estimated for non-strippable and pre-benchmark bonds, i.e. the actual liquidity premium for non-strippable bonds is higher than the estimated, whereas the absolute value of the liquidity premium for pre-benchmark issues is lower. However, these biases in the liquidity premia should be relatively small given the very small size of the bias in quoted prices. Consequently, the reported results of sections 5.1 to 5.5 seem to be robust to the data set we have used.

\section{CONCLUSIONS}

The analysis developed in the first part of the paper has shown that there are important liquidity differences among securities traded in the Spanish GS market. The strippability of the asset -strippable bonds are the most liquid- and the benchmark status -benchmark bonds are more liquid- appear to be two relevant determinants of the securities' liquidity within each maturity zone.

The second part of the paper analyses the presence of liquidity premia in the relative pricing of assets traded in the Spanish GS market. The estimation is carried out introducing liquidity parameters in the Svensson model of the zero-coupon yield curve. These liquidity parameters allow us to estimate the excess yield of pre-benchmark, post-benchmark and non-strippable bonds over benchmark issues. This methodology improves on the traditional approach to the estimation of liquidity premia - which involves computing the yield spread between non-benchmark and benchmark bonds - because it allows an appropriate control of effects associated with differences in maturity and cash flows.

The main conclusions that can be drawn from the estimations made are the following. First, results suggest the existence of positive liquidity premia for post-benchmark bonds (both strippable and non-strippable). However, these premia are very small and similar to those found by Elton and Green (1998) in the US market. Second, the lack of liquidity of prebenchmark bonds does not seem to be priced in the market. In fact, in some periods, there is even a negative premium over benchmark issues for these bonds. This is a somewhat surprising result that can possibly be explained by the forward-looking behaviour of market participants. Third, estimated liquidity premia seem robust to tax effects and to the data set we have used (quoted prices instead of actual traded prices). Finally, regarding the implications for the estimated zero-coupon yield curve, the introduction of liquidity effects does not have a significant impact due to the small size of the estimated liquidity premia.

In this paper we have focused on testing for the existence of liquidity premia in the Spanish GS market. The results obtained pose interesting questions for future research. One of them is the analysis of the determinants of the estimated liquidity premia and their 
dynamics. Other possible extensions include the application of the methodology used to other GS markets, or the analysis of liquidity premia during periods of financial tension. 


\section{REFERENCES}

Amihud, Y. and H. Mendelson (1986) Asset pricing and the bid-ask spread, Journal of Financial Economics 17, 223-249.

(1989) The effects of beta, bid-ask spread, residual risk and size on stock returns, Journal of Finance 44, 479-486.

(1991) Liquidity, maturity, and the yields on U.S. Treasury securities, Journal of Finance 46, pp. 1411-1425.

Bank for International Settlements (1999) Market Liquidity: Research Findings and Selected Policy Implications.

Copeland, T.C. and Galai, G. (1983) Information effects on the bid-ask spread Journal of Finance, 38, pp. 1457-1469

Elton, E. J. and T. C. Green (1998) Tax and liquidity effects in pricing government bonds, The Journal of Finance 53, 1533-1562.

Fleming, M. J. and E. M. Remolona (1996) Price formation and liquidity in the U.S. treasuries market: evidence from intraday patterns around announcements, Research Paper 9633, Federal Reserve Bank of New York.

Garbade, K. D. (1996) Fixed Income Analysis (MIT Press, Cambridge, Mass.)

Gravelle, T. (1999) Liquidity of the government of Canada Securities Market: stylized facts and some market microstructure comparisons to the United States Treasury Market, Bank of Canada, Working Paper 99-11.

Kamara, A. (1994) Liquidity, taxes, and short-term Treasury yields, Journal of Financial and Quantitative Analysis 29, 403-417.

Litzenberger, R. H. and J. Rolfo (1984) An international study of tax effects on government bonds, The Journal of Finance 39, 1-22.

Nelson C. R. and A. F. Siegel (1987) Parsimonious Modelling of yield curves for US Treasury Bills, Journal of Business 60, 473-489. 
Núñez, S. (1995) Estimación de la estructura temporal de los tipos de interés en España: elección entre métodos alternativos, Banco de España, Documento de Trabajo no 9522.

Sarig, O. and A. Warga (1989) Bond price data and bond market liquidity, Journal of Financial and Quantitative Analysis 24, 367-378.

Shen, P. and R. M. Starr (1998) Liquidity of the Treasury bill market and the term structure of interest rates, Journal of Economics and Business 50, pp. 401-417.

Svensson, L.E.O. (1994) Estimating and interpreting forward interest rates: Sweden 19921994, Centre for Economic Policy Research, Discussion Paper 1051.

Warga, A. (1992) Bond returns, liquidity, and missing data, Journal of Financial and Quantitative Analysis 27, 605-617. 


\section{ANNEX 1: THE SVENSSON MODEL}

Svensson (1994) specifies a smooth parametric function for the yield curve. The functional form for the instantaneous forward rate of term $m, \varphi_{m}$, is the following:

$$
\varphi_{m}(\beta)=\beta_{0}+\beta_{1} e^{-\frac{m}{\tau_{1}}}+\beta_{2} \frac{m}{\tau_{1}} e^{-\frac{m}{\tau_{1}}}+\beta_{3} \frac{m}{\tau_{2}} e^{-\frac{m}{\tau_{2}}}
$$

where $\beta=\left(\beta_{0}, \beta_{1}, \beta_{2}, \tau_{1}, \beta_{3}, \tau_{2}\right)$ is the vector of parameters.

$m \quad$ is the term to maturity.

$\beta_{0}=\varphi_{\infty} \quad$ is the asymptotic value of the instantaneous forward rate.

$\beta_{0}+\beta_{1}=\varphi_{0}$ is the instantaneous forward rate for an infinitely small term to maturity.

$\tau_{1} \quad$ indicates the position of the first internal maximum or minimum.

$\beta_{2} \quad$ determines the magnitude and direction of the first hump. If $\beta_{2}>0$, there is a maximum at $\tau_{1}$, and a minimum if $\beta_{2}<0$.

$\tau_{2} \quad$ indicates the position of the second internal maximum or minimum.

$\beta_{3} \quad$ determines the magnitude and direction of the second hump. If $\beta_{3}>0$, there is a maximum at $\tau_{2}$, and a minimum if $\beta_{3}<0$.

The zero-coupon rate is the mean of integration of the instantaneous forward rate between period 0 and the term to maturity, $r_{m}=\frac{1}{m} \int_{0}^{m} \varphi_{\theta} d \theta$ :

$$
r_{m}(\beta)=\beta_{0}+\left(\beta_{1}+\beta_{2}\right) \frac{\tau_{1}}{m}\left(1-e^{-\frac{m}{\tau_{1}}}\right)-\beta_{2} e^{-\frac{m}{\tau_{1}}}+\beta_{3} \frac{\tau_{2}}{m}\left(1-e^{-\frac{m}{\tau_{2}}}\right)-\beta_{3} e^{-\frac{m}{\tau_{2}}}
$$

The continuously compounded discount factor is $d(m)=e^{-m r_{m}}$ :

$$
d(m, \beta)=e^{-\beta_{0} m-\left(\beta_{1}+\beta_{2}\right) \tau_{1}\left(1-e^{-\frac{m}{\tau_{1}}}\right)+\beta_{2} m e^{-\frac{m}{\tau_{1}}}-\beta_{3} \tau_{2}\left(1-e^{-\frac{m}{\tau_{2}}}\right)+\beta_{3} m e^{-\frac{m}{\tau_{2}}}}
$$

The theoretical price of bond $i$ at time $t$ is the present value of its cash flows: 


$$
p_{i t}(\beta)=\sum_{j=t}^{M} d(j-t, \beta) f_{i j}
$$

where $f_{i j}$ represents the coupon and principal payments of bond $i$ at date $j$, and $M$ is the redemption date.

The parameter vector is estimated by the minimisation of some distance between the theoretical and actual prices of the bonds. Sometimes the minimisation problem is specified in terms of yield errors instead of price errors, or some combination of both. Another possibility is estimation by maximum likelihood. 
Table 1: Turnover in the Spanish government securities market

1999, EUR millions

\begin{tabular}{|c|c|c|c|}
\hline & TOTAL & $\begin{array}{l}\text { Between market } \\
\text { members }\end{array}$ & $\begin{array}{l}\text { Through registered } \\
\text { dealers }\end{array}$ \\
\hline Outright spot purchases & $1,817,465$ & 498,958 & $1,318,507$ \\
\hline Bills & 79,839 & 31,609 & 48,230 \\
\hline Bonds & $1,737,626$ & 467,349 & $1,270,277$ \\
\hline Repo transactions & $11,254,309$ & $2,785,567$ & $8,468,742$ \\
\hline Forward transactions & 37,901 & - - & - - \\
\hline Futures and options transactions & 356,146 & - - & - - \\
\hline
\end{tabular}

Source: Banco de España

Table 2: Holders of Spanish government securities

End-1999, percentages

\begin{tabular}{lrr}
\hline & Bills & Bonds \\
\hline Banking sector & 49.5 & 31.1 \\
Other financial institutions & 41.8 & 30.1 \\
$\quad$ Mutual funds & 35.8 & 16.8 \\
$\quad$ Pension funds & 0.5 & 2.9 \\
$\quad$ Insurance companies & 0.3 & 10.1 \\
$\quad$ Other & 5.2 & 0.3 \\
Non-financial corporations & 1.7 & 3.8 \\
Households & 4.6 & 1.2 \\
Non-residents & 2.3 & 32.0 \\
Other & 0.1 & 1.8 \\
\hline
\end{tabular}

Source: Banco de España. 
Table 3: Bonds included in the sample

\begin{tabular}{|c|c|c|c|}
\hline Coupon (\%) & Issue Date & Maturity Date & $\begin{array}{c}\text { Remaining life at } \\
4 / 1 / 99 \text { (vears) }\end{array}$ \\
\hline 10.65 & $30 / 07 / 86$ & $30 / 07 / 01$ & 2.57 \\
\hline 12.25 & $25 / 03 / 90$ & $25 / 03 / 00$ & 1.22 \\
\hline 11.3 & $15 / 11 / 91$ & $15 / 01 / 02$ & 3.03 \\
\hline 10.3 & $15 / 04 / 92$ & $15 / 06 / 02$ & 3.45 \\
\hline 10.9 & $15 / 02 / 93$ & $30 / 08 / 03$ & 4.65 \\
\hline 10.5 & $17 / 05 / 93$ & $30 / 10 / 03$ & 4.82 \\
\hline 8.2 & $15 / 12 / 93$ & $28 / 02 / 09$ & 10.16 \\
\hline 8 & $17 / 01 / 94$ & $30 / 05 / 04$ & 5.41 \\
\hline 7.4 & $15 / 02 / 94$ & $30 / 07 / 99$ & 0.57 \\
\hline 10 & $15 / 11 / 94$ & 28/02/05 & 6.16 \\
\hline 10.1 & $15 / 09 / 95$ & $28 / 02 / 01$ & 2.15 \\
\hline 10.15 & $15 / 09 / 95$ & $31 / 01 / 06$ & 7.08 \\
\hline 9.4 & $15 / 12 / 95$ & $30 / 04 / 99$ & 0.32 \\
\hline 8.4 & $15 / 03 / 96$ & $30 / 04 / 01$ & 2.32 \\
\hline 8.8 & $15 / 03 / 96$ & $30 / 04 / 06$ & 7.32 \\
\hline 7.8 & $17 / 06 / 96$ & $31 / 10 / 99$ & 0.82 \\
\hline 8.7 & $15 / 07 / 96$ & $28 / 02 / 12$ & 13.16 \\
\hline 7.9 & $15 / 10 / 96$ & $28 / 02 / 02$ & 3.15 \\
\hline 6.75 & $15 / 11 / 96$ & $15 / 04 / 00$ & 1.28 \\
\hline 7.35 & $16 / 12 / 96$ & $31 / 03 / 07$ & 8.24 \\
\hline 5 & $15 / 07 / 97$ & $31 / 01 / 01$ & 2.08 \\
\hline 5.25 & $15 / 07 / 97$ & $31 / 01 / 03$ & 4.08 \\
\hline 6 & $15 / 07 / 97$ & $31 / 01 / 08$ & 9.08 \\
\hline 6.15 & $15 / 07 / 97$ & $31 / 01 / 13$ & 14.08 \\
\hline 6 & $15 / 01 / 98$ & $31 / 01 / 29$ & 30.10 \\
\hline 5.15 & $10 / 07 / 98$ & $30 / 07 / 09$ & 10.58 \\
\hline 4.25 & $7 / 08 / 98$ & $30 / 07 / 02$ & 3.57 \\
\hline 4.5 & $10 / 08 / 98$ & $30 / 07 / 04$ & 5.57 \\
\hline 4.75 & $7 / 12 / 98$ & $30 / 07 / 14$ & 15.58 \\
\hline 4 & $11 / 05 / 99$ & $31 / 01 / 10$ & 11.08 \\
\hline 3 & $13 / 07 / 99$ & $31 / 01 / 03$ & 4.08 \\
\hline 3.25 & $12 / 07 / 99$ & $31 / 01 / 05$ & 6.08 \\
\hline 4.6 & $15 / 02 / 00$ & $30 / 07 / 03$ & 4.57 \\
\hline 4.95 & $14 / 02 / 00$ & $30 / 07 / 05$ & 6.57 \\
\hline
\end{tabular}


Table 4: Dates of changes in benchmark bonds according to different criteria

\begin{tabular}{|c|c|c|c|c|c|}
\hline \multirow[b]{2}{*}{ Term } & \multicolumn{2}{|c|}{ Benchmark } & \multicolumn{3}{|c|}{ Criteria } \\
\hline & $\begin{array}{c}\text { Coupon } \\
(\%)\end{array}$ & $\begin{array}{c}\text { Maturity } \\
\text { date }\end{array}$ & Ours & Bloomberg & Reuters \\
\hline \multirow{3}{*}{3} & 5 & $31 / 1 / 01$ & & & \\
\hline & 4.25 & $30 / 7 / 02$ & 28/1/99 & 12/1/99 & 2/2/99 \\
\hline & 3 & $31 / 1 / 03$ & 2/12/99 & $4 / 1 / 00$ & 19/11/99 \\
\hline \multirow{3}{*}{5} & 5.25 & $31 / 1 / 03$ & & & \\
\hline & 4.5 & $30 / 7 / 04$ & 13/1/99 & 12/1/99 & 2/2/99 \\
\hline & 3.25 & 31/1/05 & 2/12/99 & $4 / 1 / 00$ & $19 / 11 / 99$ \\
\hline \multirow{3}{*}{10} & 6 & $31 / 1 / 08$ & & & \\
\hline & 5.15 & $30 / 7 / 09$ & $26 / 2 / 99$ & 12/1/99 & 2/2/99 \\
\hline & 4 & $31 / 1 / 10$ & $6 / 10 / 99$ & $4 / 1 / 00$ & $19 / 11 / 99$ \\
\hline \multirow{2}{*}{$15^{1}$} & 6.15 & $31 / 1 / 13$ & & & \\
\hline & 4.75 & $30 / 7 / 14$ & 2/12/99 & & \\
\hline $30^{1}$ & 6 & $31 / 1 / 29$ & & & \\
\hline
\end{tabular}

${ }^{1}$ Bloomberg and Reuters do not provide benchmark information on these terms. 
Table 5: Main figures for Spanish govt. bonds by categories and term to maturity

a) Number of issues

\begin{tabular}{|c|c|c|c|c|c|}
\hline $\begin{array}{c}\text { residual life } \\
\text { (years) }\end{array}$ & $\begin{array}{c}\text { pre- } \\
\text { benchmark }\end{array}$ & $\begin{array}{c}\text { post- } \\
\text { benchmark }\end{array}$ & $\begin{array}{c}\text { non- } \\
\text { strippable }\end{array}$ & benchmark & total \\
\hline $0-2$ & & 0.9 & 5.9 & & 6.9 \\
\hline $2-4$ & 1.0 & 1.5 & 4.8 & 1 & 8.3 \\
\hline $4-6$ & 0.5 & 0.3 & 3.1 & 1 & 4.9 \\
\hline $6-9$ & & 0.9 & 3.1 & & 4.0 \\
\hline $9-11$ & 0.4 & 0.4 & 0.8 & 1 & 2.6 \\
\hline $11-16$ & 0.7 & 0.3 & 1.0 & 1 & 3.0 \\
\hline $16-30$ & & & & 1 & 1.0 \\
\hline total & 2.6 & 4.4 & 18.7 & 5 & 30.7 \\
\hline
\end{tabular}

b) Total outstanding amount

\begin{tabular}{|c|c|c|c|c|c|}
\hline $\begin{array}{l}\text { residual life } \\
\text { (years) }\end{array}$ & $\begin{array}{c}\text { pre- } \\
\text { benchmark }\end{array}$ & $\begin{array}{c}\text { post- } \\
\text { benchmark }\end{array}$ & $\begin{array}{c}\text { non- } \\
\text { strippable }\end{array}$ & benchmark & total \\
\hline $0-2$ & & $4.7 \%$ & $13.4 \%$ & & $18.1 \%$ \\
\hline $2-4$ & $1.2 \%$ & $6.5 \%$ & $8.6 \%$ & $4.0 \%$ & $20.4 \%$ \\
\hline $4-6$ & $1.3 \%$ & $4.6 \%$ & $7.2 \%$ & $4.1 \%$ & $17.2 \%$ \\
\hline $6-9$ & & $7.9 \%$ & $7.1 \%$ & & $15.0 \%$ \\
\hline $9-11$ & $1.6 \%$ & $5.6 \%$ & $2.7 \%$ & $4.7 \%$ & $14.5 \%$ \\
\hline $\begin{array}{l}11-16 \\
16-30\end{array}$ & $1.5 \%$ & $5.0 \%$ & $0.8 \%$ & $\begin{array}{l}4.2 \% \\
3.3 \%\end{array}$ & $\begin{array}{c}11.6 \% \\
3.3 \%\end{array}$ \\
\hline total & $5.6 \%$ & $34.3 \%$ & $39.7 \%$ & $20.3 \%$ & $100 \%$ \\
\hline
\end{tabular}

c) Aggregate trading volume

\begin{tabular}{|c|c|c|c|c|c|}
\hline $\begin{array}{c}\text { residual life } \\
\text { (years) }\end{array}$ & $\begin{array}{c}\text { pre- } \\
\text { benchmark }\end{array}$ & $\begin{array}{c}\text { post- } \\
\text { benchmark }\end{array}$ & $\begin{array}{c}\text { non- } \\
\text { strippable }\end{array}$ & benchmark & total \\
\hline $0-2$ & & $4.5 \%$ & $2.1 \%$ & & $6.6 \%$ \\
\hline $2-4$ & $2.9 \%$ & $6.8 \%$ & $2.2 \%$ & $12.7 \%$ & $24.7 \%$ \\
\hline $4-6$ & $3.5 \%$ & $4.2 \%$ & $0.7 \%$ & $14.6 \%$ & $23.0 \%$ \\
\hline $6-9$ & & $3.5 \%$ & $1.7 \%$ & & $5.3 \%$ \\
\hline $9-11$ & $7.6 \%$ & $4.4 \%$ & $0.1 \%$ & $20.4 \%$ & $32.6 \%$ \\
\hline $\begin{array}{l}11-16 \\
16-30\end{array}$ & $1.0 \%$ & $1.4 \%$ & $0.3 \%$ & $\begin{array}{l}2.6 \% \\
2.5 \%\end{array}$ & $\begin{array}{l}5.4 \% \\
2.5 \%\end{array}$ \\
\hline total & $15.0 \%$ & $24.9 \%$ & $7.3 \%$ & $52.9 \%$ & $100 \%$ \\
\hline
\end{tabular}

d) Total number of trades

\begin{tabular}{|c|c|c|c|c|c|}
\hline $\begin{array}{c}\text { residual life } \\
\text { (years) }\end{array}$ & $\begin{array}{c}\text { pre- } \\
\text { benchmark }\end{array}$ & $\begin{array}{c}\text { post- } \\
\text { benchmark }\end{array}$ & $\begin{array}{c}\text { non- } \\
\text { strippable }\end{array}$ & benchmark & total \\
\hline $0-2$ & & $3.4 \%$ & $1.4 \%$ & & $4.8 \%$ \\
\hline $2-4$ & $1.8 \%$ & $6.5 \%$ & $1.9 \%$ & $12.5 \%$ & $22.6 \%$ \\
\hline $4-6$ & $3.5 \%$ & $5.1 \%$ & $0.8 \%$ & $15.4 \%$ & $24.8 \%$ \\
\hline $6-9$ & & $3.7 \%$ & $1.7 \%$ & & $5.4 \%$ \\
\hline $9-11$ & $6.2 \%$ & $4.8 \%$ & $0.1 \%$ & $21.9 \%$ & $33.0 \%$ \\
\hline $\begin{array}{l}11-16 \\
16-30\end{array}$ & $1.3 \%$ & $1.4 \%$ & $0.3 \%$ & $\begin{array}{l}3.2 \% \\
3.2 \%\end{array}$ & $\begin{array}{l}6.1 \% \\
3.2 \%\end{array}$ \\
\hline total & $12.8 \%$ & $24.9 \%$ & $6.2 \%$ & $56.2 \%$ & $100 \%$ \\
\hline
\end{tabular}

For each day in the sample bonds are classified according to their residual life and category. Panel (a) reports the average number of bonds in each class. In the remaining panels, activity measures are added for the bonds included in each class. Values are expressed in percentage terms with respect to the whole market. Figures in this table are averages of the daily data from January 1999 to April 2000. 
Table 6: Liquidity measures for Spanish government bonds

a) Number of transactions per bond

\begin{tabular}{|c|c|c|c|c|}
\hline $\begin{array}{l}\text { residual life } \\
\text { (years) }\end{array}$ & $\begin{array}{c}\text { pre- } \\
\text { benchmark }\end{array}$ & $\begin{array}{c}\text { post- } \\
\text { benchmark }\end{array}$ & $\begin{array}{c}\text { non- } \\
\text { strippable }\end{array}$ & benchmark \\
\hline $0-2$ & & 11.9 & 0.8 & \\
\hline $2-4$ & 4.5 & 17.4 & 1.4 & 43.9 \\
\hline $4-6$ & 6.3 & 9.5 & 0.9 & 54.3 \\
\hline $6-9$ & & 13.2 & 1.9 & \\
\hline $9-11$ & 28.0 & 17.0 & 0.5 & 77.2 \\
\hline $11-16$ & 4.6 & 4.9 & 0.9 & 11.3 \\
\hline $16-30$ & & & & 11.3 \\
\hline total & 16.5 & 16.9 & 0.3 & 39.6 \\
\hline
\end{tabular}

b) Trading volume per bond (EUR millions)

\begin{tabular}{|c|c|c|c|c|}
\hline $\begin{array}{c}\text { residual life } \\
\text { (years) }\end{array}$ & $\begin{array}{c}\text { pre- } \\
\text { benchmark }\end{array}$ & $\begin{array}{c}\text { post- } \\
\text { benchmark }\end{array}$ & $\begin{array}{c}\text { non- } \\
\text { strippable }\end{array}$ & benchmark \\
\hline $0-2$ & & 90.5 & 7.0 & \\
\hline $2-4$ & 50.0 & 106.4 & 9.5 & 258.2 \\
\hline $4-6$ & 49.5 & 55.0 & 5.3 & 295.9 \\
\hline $6-9$ & & 72.0 & 11.3 & \\
\hline $9-11$ & 199.0 & 89.8 & 2.5 & 414.3 \\
\hline $11-16$ & 20.2 & 28.5 & 6.8 & 53.6 \\
\hline $16-30$ & & & & 51.1 \\
\hline total & 45.5 & 63.2 & 6.1 & 153.3 \\
\hline
\end{tabular}

c) Turnover ratio

\begin{tabular}{|c|c|c|c|c|}
\hline $\begin{array}{c}\text { residual life } \\
\text { (years) }\end{array}$ & $\begin{array}{c}\text { pre- } \\
\text { benchmark }\end{array}$ & $\begin{array}{c}\text { post- } \\
\text { benchmark }\end{array}$ & $\begin{array}{c}\text { non- } \\
\text { strippable }\end{array}$ & benchmark \\
\hline $0-2$ & & $0.9 \%$ & $0.1 \%$ & \\
\hline $2-4$ & $2.1 \%$ & $1.0 \%$ & $0.2 \%$ & $2.9 \%$ \\
\hline $4-6$ & $2.5 \%$ & $0.8 \%$ & $0.1 \%$ & $3.2 \%$ \\
\hline $6-9$ & & $0.4 \%$ & $0.2 \%$ & \\
\hline $9-11$ & $4.3 \%$ & $0.7 \%$ & $0.0 \%$ & $4.0 \%$ \\
\hline $11-16$ & $0.6 \%$ & $0.3 \%$ & $0.4 \%$ & $0.6 \%$ \\
\hline $16-30$ & & & & $0.7 \%$ \\
\hline total & $2.4 \%$ & $0.7 \%$ & $0.2 \%$ & $2.3 \%$ \\
\hline
\end{tabular}

For each day in the sample bonds are classified according to their residual life and category. For each class we compute the average of the activity measures for the bonds included. Figures in this table are averages of the daily data from January 1999 to April 2000. 
Table 7: Errors in the estimated zero-coupon yield curve

\begin{tabular}{|c|c|c|c|c|c|c|}
\hline \multicolumn{3}{|c|}{ Issue } & \multicolumn{4}{|c|}{ Average estimated yield errors (basis points) } \\
\hline Coupon (\%) & Maturity Date & $\begin{array}{l}\text { Average } \\
\text { Duration }\end{array}$ & pre-bench & benchmark & post-bench & non-strip \\
\hline 9.4 & $30 / 4 / 99$ & 0.16 & & & & 67.7 \\
\hline 7.4 & $30 / 7 / 99$ & 0.29 & & & & 29.4 \\
\hline 7.8 & $31 / 10 / 99$ & 0.42 & & & & 20.7 \\
\hline 12.25 & $25 / 3 / 00$ & 0.60 & & & & 5.5 \\
\hline 6.75 & $15 / 4 / 00$ & 0.63 & & & & 5.4 \\
\hline 5 & $31 / 1 / 01$ & 1.39 & & -0.6 & -2.3 & \\
\hline 10.1 & $28 / 2 / 01$ & 1.42 & & & & 1.6 \\
\hline 8.4 & $30 / 4 / 01$ & 1.58 & & & & -3.1 \\
\hline 11.3 & $15 / 1 / 02$ & 2.16 & & & & 2.4 \\
\hline 7.9 & $28 / 2 / 02$ & 2.31 & & & & 1.1 \\
\hline 10.3 & $15 / 6 / 02$ & 2.49 & & & & 1.5 \\
\hline 4.25 & $30 / 7 / 02$ & 2.81 & -7.5 & -3.8 & -3.6 & \\
\hline 3 & $31 / 1 / 03$ & 3.09 & -3.5 & 0.0 & & \\
\hline 5.25 & $31 / 1 / 03$ & 3.17 & & -8.0 & -3.8 & \\
\hline 4.6 & $30 / 7 / 03$ & 3.26 & -1.4 & & & \\
\hline 10.9 & $30 / 8 / 03$ & 3.39 & & & & 0.9 \\
\hline 10.5 & $30 / 10 / 03$ & 3.53 & & & & 0.8 \\
\hline 8 & $30 / 5 / 04$ & 4.05 & & & & -2.1 \\
\hline 10 & $28 / 2 / 05$ & 4.46 & & & & 2.6 \\
\hline 4.5 & $30 / 7 / 04$ & 4.52 & -14.0 & -9.3 & -4.6 & \\
\hline 3.25 & $31 / 1 / 05$ & 4.86 & -4.8 & -3.4 & & \\
\hline 4.95 & $30 / 7 / 05$ & 4.94 & -4.7 & & & \\
\hline 10.15 & $31 / 1 / 06$ & 5.05 & & & & 5.2 \\
\hline 8.8 & $30 / 4 / 06$ & 5.28 & & & & 2.8 \\
\hline 7.35 & $31 / 3 / 07$ & 6.01 & & & & 3.3 \\
\hline 6 & $31 / 1 / 08$ & 6.77 & & 3.1 & 4.0 & \\
\hline 8.2 & $28 / 2 / 09$ & 7.04 & & & & 1.3 \\
\hline 5.15 & $30 / 7 / 09$ & 8.02 & -7.0 & -4.3 & -4.1 & \\
\hline 4 & $31 / 1 / 10$ & 8.43 & -7.2 & -6.5 & & \\
\hline 8.7 & $28 / 2 / 12$ & 8.44 & & & & 5.3 \\
\hline 6.15 & $31 / 1 / 13$ & 9.48 & & 2.1 & 2.2 & \\
\hline 4.75 & $30 / 7 / 14$ & 10.87 & -2.1 & -1.3 & & \\
\hline 6 & $31 / 1 / 29$ & 14.57 & & 0.0 & & \\
\hline & Average & & -5.8 & -2.7 & -1.8 & 8.0 \\
\hline
\end{tabular}

Figures are average of daily errors. Zero-coupon yield curves are estimated using the Svensson model for the whole sample. 
Table 8: Liquidity premia estimates (basis points)

\begin{tabular}{|c|c|c|c|c|c|c|}
\hline & \multirow{2}{*}{$\begin{array}{c}\text { Model } 1 \\
\text { Basic Model }\end{array}$} & \multicolumn{3}{|c|}{ Model 2} & \multicolumn{2}{|c|}{ Model 3} \\
\hline & & $\gamma_{0}$ & $\gamma_{1}$ & $\gamma_{2}$ & $\gamma_{1}$ & $\gamma_{2}$ \\
\hline Mean & & -2.7 & 4.4 & 6.9 & 5.2 & 8.0 \\
\hline Max. & & 4.5 & 10.7 & 10.4 & 12.5 & 11.7 \\
\hline Min. & & -11.1 & -6.0 & 2.5 & -3.6 & 5.1 \\
\hline Std.Dev. & & 3.9 & 3.5 & 1.7 & 4.0 & 1.6 \\
\hline$\%$ Signif. (-) & & $55 \%$ & $0 \%$ & $0 \%$ & $0 \%$ & $0 \%$ \\
\hline$\%$ Signif. (+) & & $2 \%$ & $74 \%$ & $99 \%$ & $77 \%$ & $100 \%$ \\
\hline Mean RMSE & 1.63 & \multirow{2}{*}{\multicolumn{3}{|c|}{$\begin{array}{c}0.60 \\
63.29 \%\end{array}$}} & \multirow{2}{*}{\multicolumn{2}{|c|}{$\begin{array}{c}0.81 \\
50.18 \%\end{array}$}} \\
\hline $\begin{array}{l}\text { Mean error } \\
\text { reduction (\%) }\end{array}$ & & & & & & \\
\hline
\end{tabular}

Zero-coupon yield curves are estimated using the Nelson-Siegel model until September 1999 and the Svensson model thereafter. Dummy variables are introduced to capture liquidity differences. The instantaneous forward rate of term $m$ is modelled in the following way for the Svensson model:

$\varphi_{m}=\beta_{0}+\beta_{1} e^{-\frac{m}{\tau_{1}}}+\beta_{2} \frac{m}{\tau_{1}} e^{-\frac{m}{\tau_{1}}}+\beta_{3} \frac{m}{\tau_{2}} e^{-\frac{m}{\tau_{2}}}+\gamma_{0}$ PREBENCH $+\gamma_{1}$ POSTBENCH $+\gamma_{2}$ NONSTRIP

Model 1 (basic model) does not consider any liquidity effect, i.e. $\gamma_{0}, \gamma_{1}$ and $\gamma_{2}$ are restricted to zero. Model 2 estimates all parameters freely. Model 3 eliminates the dummy variable for pre-benchmark bonds, $\gamma_{0}$. Premium figures are expressed in basis points. Mean error reduction refers to the reduction of RMSE with respect to the basic model. 
Table 9: Impact of withholding tax on liquidity premia estimates (basis points)

\begin{tabular}{|c|c|c|c|c|c|c|}
\hline & \multicolumn{6}{|c|}{ Model 4} \\
\hline & \multicolumn{2}{|c|}{ Annual tax payment } & \multicolumn{2}{|c|}{ Quarterly tax payment } & \multicolumn{2}{|c|}{$\begin{array}{c}\text { Scenario } 3 \\
\text { Annual tax payment with } \\
\text { coupon-washing } \\
\text { transactions }\end{array}$} \\
\hline & $\gamma_{1}$ & $\gamma_{2}$ & $\gamma_{1}$ & $\gamma_{2}$ & $\gamma_{1}$ & $\gamma_{2}$ \\
\hline Mean & 5.1 & -0.7 & 5.4 & 6.8 & 5.2 & 3.6 \\
\hline Max. & 12.3 & 4.1 & 12.6 & 10.5 & 12.5 & 7.8 \\
\hline Min. & -4.3 & -4.9 & -3.4 & 3.8 & -4.1 & 0.2 \\
\hline & 4.0 & 2.5 & 4.0 & 1.7 & 4.0 & 2.0 \\
\hline \% Signif. (-) & $0 \%$ & $34 \%$ & $0 \%$ & $0 \%$ & $0 \%$ & $0 \%$ \\
\hline \% Signif._t $( \pm)$ & $78 \%$ & $17 \%$ & $78 \%$ & $100 \%$ & $78 \%$ & $75 \%$ \\
\hline Mean RMSE & & & & & & \\
\hline $\begin{array}{l}\text { Mean error } \\
\text { reduction (\%) }\end{array}$ & & & & & & \\
\hline
\end{tabular}

Zero-coupon yield curves are estimated using the Nelson-Siegel model until September 1999 and the Svensson model thereafter. Dummy variables are introduced to capture liquidity differences. The instantaneous forward rate of term $m$ is modelled in the following way for the Svensson model:

$\varphi_{m}=\beta_{0}+\beta_{1} e^{-\frac{m}{\tau_{1}}}+\beta_{2} \frac{m}{\tau_{1}} e^{-\frac{m}{\tau_{1}}}+\beta_{3} \frac{m}{\tau_{2}} e^{-\frac{m}{\tau_{2}}}+\gamma_{1}$ POSTBENCH $+\gamma_{2}$ NONSTRIP

Liquidity premium figures are expressed in basis points. Mean error reduction refers to the reduction of the RMSE with respect the basic model (Model 1). Model 4 is the same as Model 3, but taking into account withholding tax effects for non-strippable bonds. We consider three alternative tax scenarios. Under scenario 1 the withholding tax is set off against the annual payment of corporate income tax. Under scenario 2 the set-off is made against the quarterly payments of the tax. Scenario 3 is the same as scenario 1, but assuming coupon-washing transactions are conducted, in which the saved cost is shared by the resident and non-resident equally. 
Table 10: Impact of taxes on liquidity premia estimates (basis points)

\begin{tabular}{|l|cc|}
\hline & \multicolumn{2}{|c|}{ Model 5 } \\
& $\gamma_{1}$ & $\gamma_{2}$ \\
\hline Mean & 3.3 & 5.0 \\
Max. & 8.1 & 7.4 \\
Min. & -2.2 & 3.2 \\
s.d. & 2.6 & 1.0 \\
\% Signif. (-) & $0 \%$ & $0 \%$ \\
\% Signif. (+) & $76 \%$ & $100 \%$ \\
\hline Mean RMSE & \multicolumn{2}{|c|}{0.38} \\
Mean error & \multicolumn{2}{|c|}{$76.37 \%$} \\
reduction (\%) & \multicolumn{3}{|c}{} \\
\hline
\end{tabular}

Zero-coupon yield curves are estimated using the Nelson-Siegel model until September 1999 and the Svensson model thereafter. Dummy variables are introduced to capture liquidity differences. The instantaneous forward rate of term $m$ is modelled in the following way for the Svensson model:

$\varphi_{m}=\beta_{0}+\beta_{1} e^{-\frac{m}{\tau_{1}}}+\beta_{2} \frac{m}{\tau_{1}} e^{-\frac{m}{\tau_{1}}}+\beta_{3} \frac{m}{\tau_{2}} e^{-\frac{m}{\tau_{2}}}+\gamma_{1}$ POSTBENCH $+\gamma_{2}$ NONSTRIP

Model 5 is the same as Model 3 but using after-tax cash flows. Liquidity premium figures are expressed in basis points. Mean error reduction refers to the reduction of the RMSE with respect to the basic model (Model 1).

Table 11: Relative liquidity premia with and without taxes (percentage points)

\begin{tabular}{|c|c|c|c|c|}
\hline & $\gamma_{1} / \beta_{0}$ & $\gamma_{2} / \beta_{0}$ & $\gamma_{1} /\left(\beta_{0}+\beta_{1}\right)$ & $\gamma_{2} /\left(\beta_{0}+\beta_{1}\right)$ \\
\hline $\begin{array}{c}\text { Model 3, before-tax } \\
\text { yield curve } \\
\begin{array}{c}\text { Model 5, after-tax } \\
\text { yield curve }\end{array}\end{array}$ & 0.84 & 1.26 & 2.05 & 3.04 \\
\hline
\end{tabular}


Table 12: Estimated parameters in different term-structure models

\begin{tabular}{|c|c|c|c|c|c|c|c|c|c|c|c|c|c|}
\hline & & \multicolumn{2}{|c|}{$\beta_{0}$} & \multicolumn{2}{|c|}{$\beta_{1}$} & \multicolumn{2}{|c|}{$\beta_{2}$} & \multicolumn{2}{|c|}{$\tau_{1}$} & \multicolumn{2}{|c|}{$\beta_{3}$} & \multicolumn{2}{|c|}{$\tau_{2}$} \\
\hline & & mean & s.d. & mean & s.d. & mean & s.d. & mean & s.d. & mean & s.d. & mean & s.d. \\
\hline \multirow[t]{2}{*}{ Model 1} & & 6.23 & 0.18 & -3.72 & 0.16 & -0.77 & 1.27 & 4.79 & 2.30 & & & & \\
\hline & $1 / 10 / 99-14 / 4 / 00$ & 6.41 & 0.23 & -3.25 & 0.58 & 40.63 & 0.37 & 2.85 & 1.02 & -40.43 & 0.36 & 2.91 & 1.05 \\
\hline \multirow[t]{2}{*}{ Model 2} & & 6.17 & 0.27 & -3.60 & 0.34 & -1.93 & 1.56 & 3.29 & 0.65 & & & & \\
\hline & $1 / 10 / 99-14 / 4 / 00$ & 6.43 & 0.25 & -3.40 & 0.61 & 40.62 & 0.97 & 2.33 & 0.39 & -40.82 & 1.10 & 2.38 & 0.39 \\
\hline \multirow[t]{2}{*}{ Model 3} & & 6.28 & 0.21 & -3.79 & 0.19 & -1.33 & 1.46 & 4.24 & 1.77 & & & & \\
\hline & $1 / 10 / 99-14 / 4 / 00$ & 6.42 & 0.24 & -3.40 & 0.61 & 40.70 & 1.10 & 2.31 & 0.40 & -40.89 & 1.24 & 2.36 & 0.40 \\
\hline \multirow[t]{2}{*}{ Model 4} & 4/1/99-30/9/99 & 6.28 & 0.20 & -3.80 & 0.19 & -1.29 & 1.47 & 4.29 & 1.83 & & & & \\
\hline & $1 / 10 / 99-14 / 4 / 00$ & 6.42 & 0.24 & -3.41 & 0.60 & 40.40 & 0.28 & 2.23 & 0.40 & -40.65 & 0.27 & 2.28 & 0.39 \\
\hline \multirow[t]{2}{*}{ Model 5} & 4/1/99-30/9/99 & 3.92 & 0.15 & -2.28 & 0.16 & -0.77 & 1.16 & 3.86 & 1.40 & & & & \\
\hline & $1 / 10 / 99-14 / 4 / 00$ & 4.11 & 0.14 & -2.14 & 0.38 & 40.45 & 0.16 & 2.06 & 0.36 & -40.59 & 0.16 & 2.09 & 0.36 \\
\hline
\end{tabular}

Zero-coupon yield curves are estimated using the Nelson-Siegel model until September 1999 and the Svensson model thereafter. Dummy variables are introduced to capture liquidity differences. The instantaneous forward rate of term $m$ is modelled in the following way for the Svensson model:

$\varphi_{m}=\beta_{0}+\beta_{1} e^{-\frac{m}{\tau_{1}}}+\beta_{2} \frac{m}{\tau_{1}} e^{-\frac{m}{\tau_{1}}}+\beta_{3} \frac{m}{\tau_{2}} e^{-\frac{m}{\tau_{2}}}+\gamma_{0}$ PREBENCH $+\gamma_{1}$ POSTBENCH $+\gamma_{2}$ NONSTRIP

Model 1 (basic model) does not consider any liquidity effect i.e. $\gamma_{0}, \gamma_{1}$ and $\gamma_{2}$ are restricted to zero. Model 2 estimates all parameters freely. Model 3 eliminates the dummy variable for pre-benchmark bonds, $\gamma_{0}$. Model 4 is the same as Model 3 , but taking into account withholding tax effects for non-strippable bonds (scenario 2: quarterly tax payments and no couponwashing transactions). Model 5 is the same as Model 3 for after-tax cash flows. Interest rates are expressed in percentage points. 
Table 13: Biases in quoted prices

\begin{tabular}{|c|c|c|c|c|c|c|}
\hline \multicolumn{3}{|c|}{ Issue } & \multicolumn{4}{|c|}{ Average differences in yield (basis points) } \\
\hline Coupon (\%) & Maturity Date & $\begin{array}{l}\text { Average } \\
\text { Duration }\end{array}$ & pre-bench & benchmark & post-bench & non-strip \\
\hline 9.4 & $30 / 4 / 99$ & 0.16 & & & & $36.5^{\star *}$ \\
\hline 7.4 & $30 / 7 / 99$ & 0.29 & & & & $19.5^{\star *}$ \\
\hline 7.8 & $31 / 10 / 99$ & 0.42 & & & & 4.7 \\
\hline 12.25 & $25 / 3 / 00$ & 0.60 & & & & $18.3^{*}$ \\
\hline 6.75 & $15 / 4 / 00$ & 0.63 & & & & $6.6^{*}$ \\
\hline 5 & $31 / 1 / 01$ & 1.39 & & 0.2 & 0.1 & \\
\hline 10.1 & $28 / 2 / 01$ & 1.42 & & & & $1.3^{*}$ \\
\hline 8.4 & $30 / 4 / 01$ & 1.58 & & & & $1.2^{*}$ \\
\hline 11.3 & $15 / 1 / 02$ & 2.16 & & & & 0.2 \\
\hline 7.9 & $28 / 2 / 02$ & 2.31 & & & & 0.2 \\
\hline 10.3 & $15 / 6 / 02$ & 2.49 & & & & 0.4 \\
\hline 4.25 & $30 / 7 / 02$ & 2.81 & $1.0^{*}$ & 0.0 & 0.1 & \\
\hline 3 & $31 / 1 / 03$ & 3.09 & $1.9^{*}$ & $0.8^{*}$ & & \\
\hline 5.25 & $31 / 1 / 03$ & 3.17 & & -1.1 & 0.2 & \\
\hline 4.6 & $30 / 7 / 03$ & 3.26 & 0.0 & & & \\
\hline 10.9 & $30 / 8 / 03$ & 3.39 & & & & $0.6^{\star *}$ \\
\hline 10.5 & $30 / 10 / 03$ & 3.53 & & & & 0.4 \\
\hline 8 & $30 / 5 / 04$ & 4.05 & & & & 0.2 \\
\hline 10 & $28 / 2 / 05$ & 4.46 & & & & 0.1 \\
\hline 4.5 & $30 / 7 / 04$ & 4.52 & -0.1 & 0.0 & 0.3 & \\
\hline 3.25 & $31 / 1 / 05$ & 4.86 & $2.3^{*}$ & 0.5 & & \\
\hline 4.95 & $30 / 7 / 05$ & 4.94 & $1.2^{*}$ & & & \\
\hline 10.15 & $31 / 1 / 06$ & 5.05 & & & & -0.2 \\
\hline 8.8 & $30 / 4 / 06$ & 5.28 & & & & 0.0 \\
\hline 7.35 & $31 / 3 / 07$ & 6.01 & & & & 0.2 \\
\hline 6 & $31 / 1 / 08$ & 6.77 & & -0.4 & 0.1 & \\
\hline 8.2 & $28 / 2 / 09$ & 7.04 & & & & $1.1^{*}$ \\
\hline 5.15 & $30 / 7 / 09$ & 8.02 & -0.3 & -0.2 & 0.4 & \\
\hline 4 & $31 / 1 / 10$ & 8.43 & 0.3 & $0.6^{*}$ & & \\
\hline 8.7 & $28 / 2 / 12$ & 8.44 & & & & $0.9^{* *}$ \\
\hline 6.15 & $31 / 1 / 13$ & 9.48 & & 0.0 & 0.4 & \\
\hline 4.75 & $30 / 7 / 14$ & 10.87 & -0.2 & 0.0 & & \\
\hline 6 & $31 / 1 / 29$ & 14.57 & & 0.0 & & \\
\hline & Average & & 0.7 & 0.0 & 0.2 & 4.9 \\
\hline
\end{tabular}

\footnotetext{
(*) Significant at $5 \%$

${ }^{(*)}$ Significant at $10 \%$
}

For each day and security we compute the difference in yield between the mean traded price and the mid quoted price. Figures are daily averages for the whole sample period (January 1999 to April 2000). 


\section{Figure 1: Life cycle for strippable 10-year bonds included in the sample}

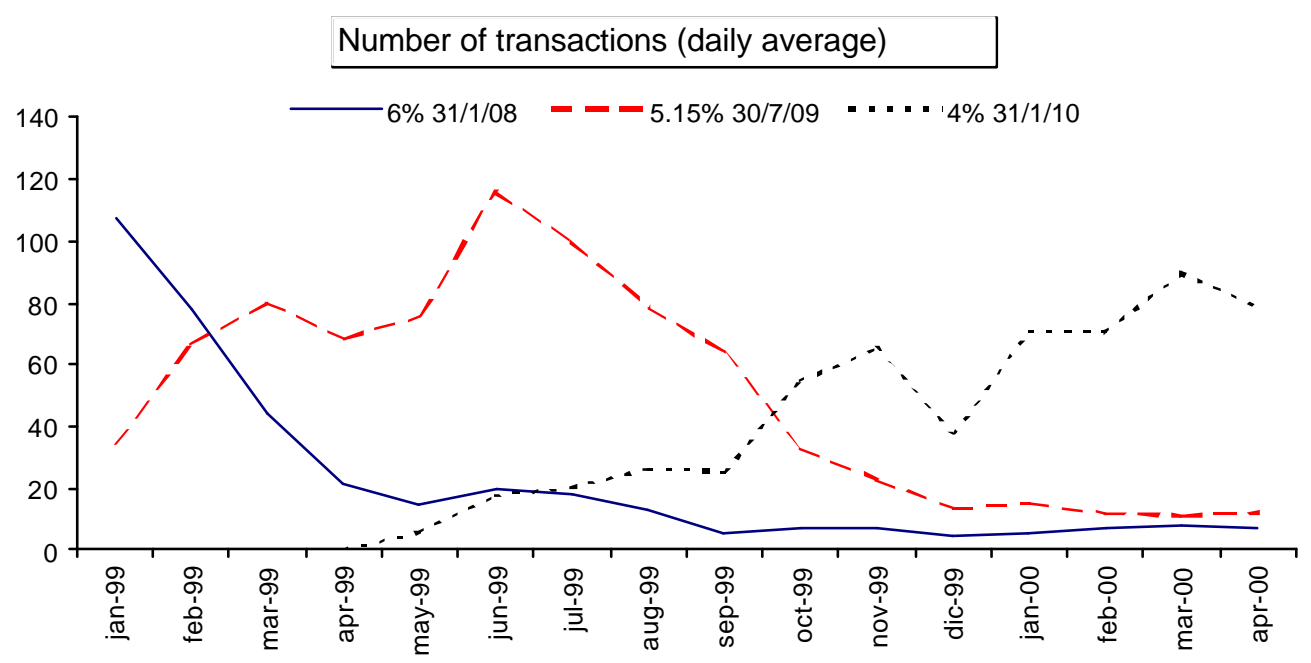

Outstanding volume
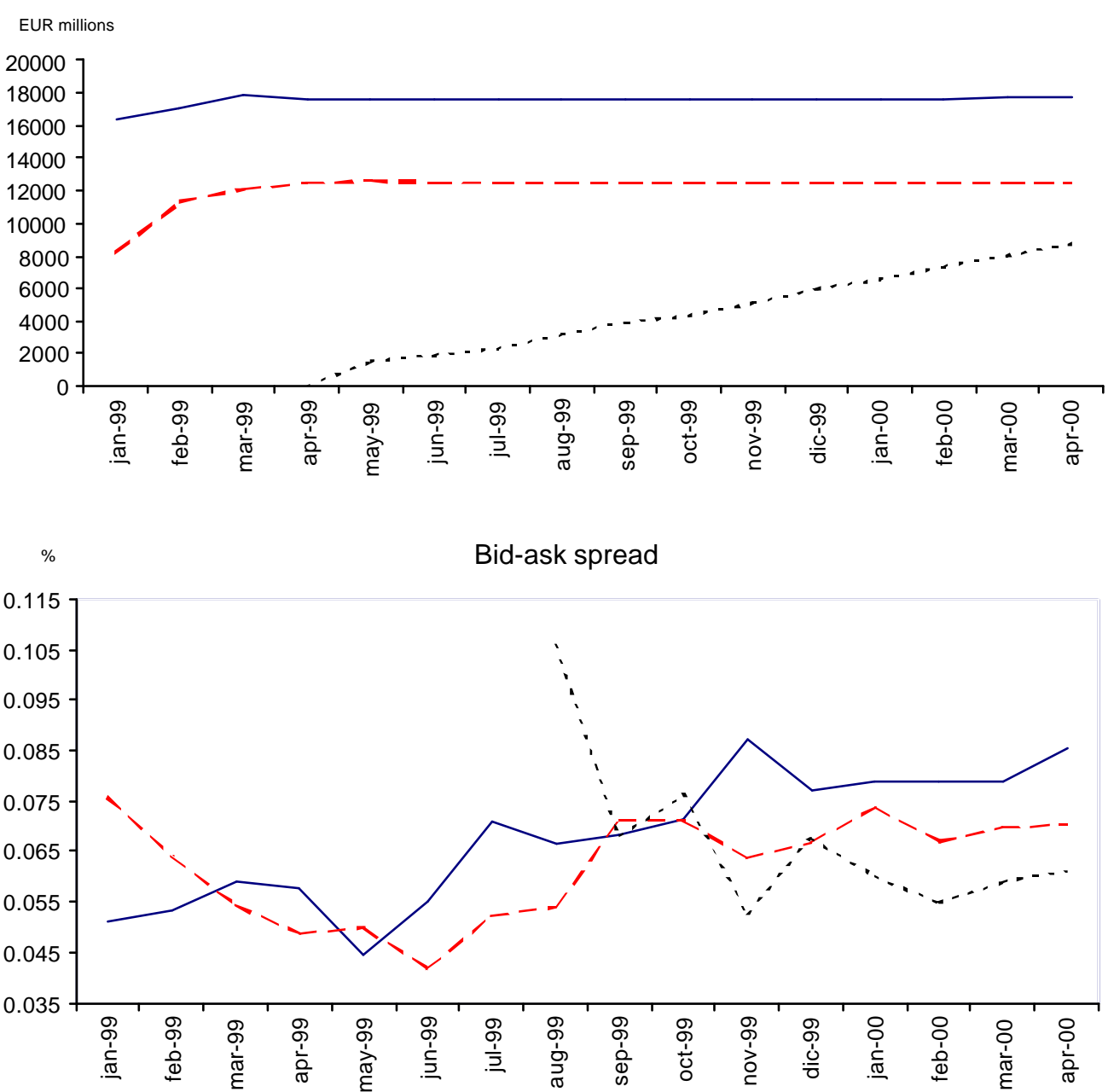
Figure 2: Average of daily bid-ask spread (percentage points)

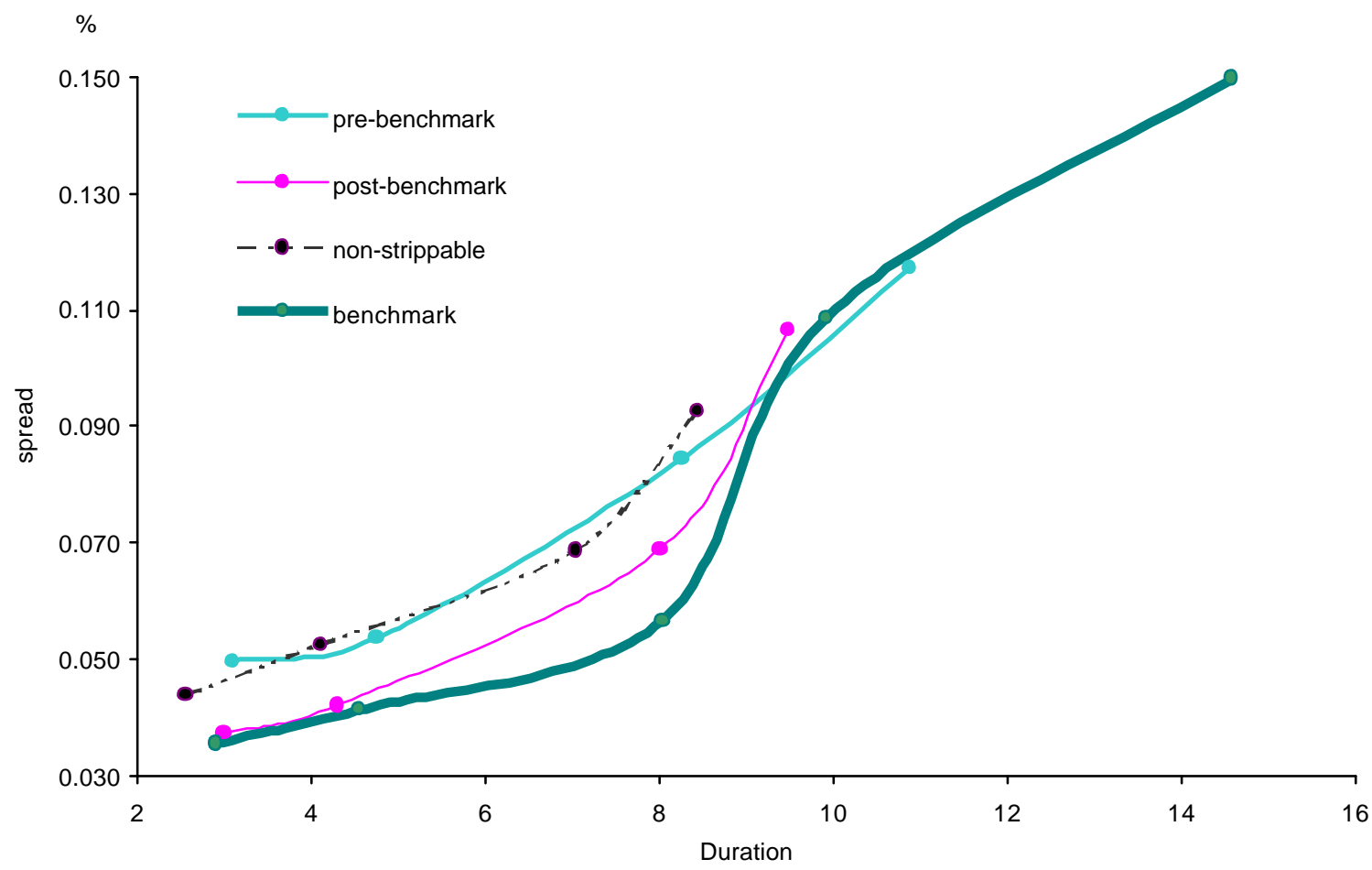

Figure 3: Zero-coupon yield curve (Nelson-Siegel model, 29th March 1999)

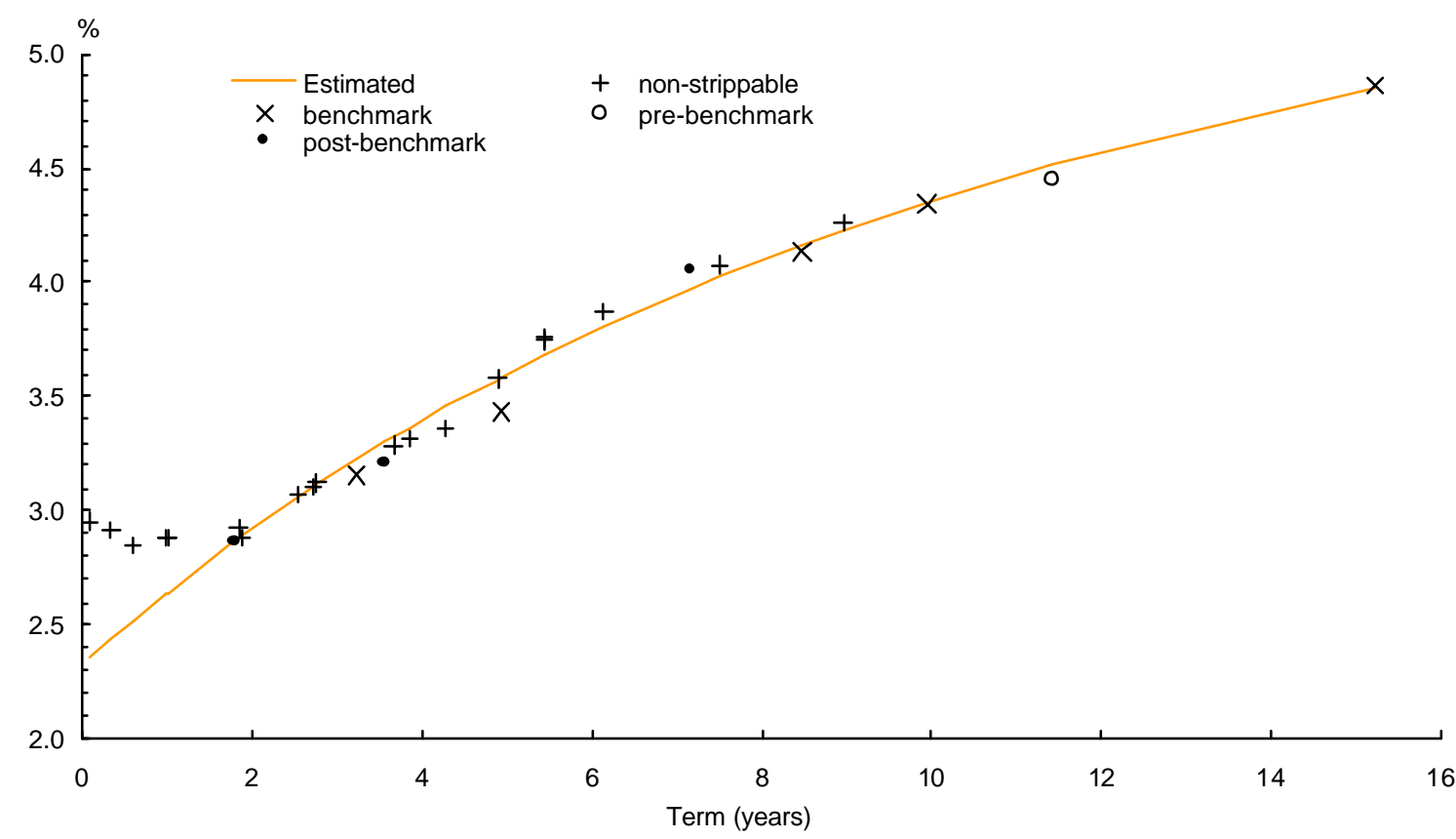




\section{Figure 4: Evolution of estimated parameters}

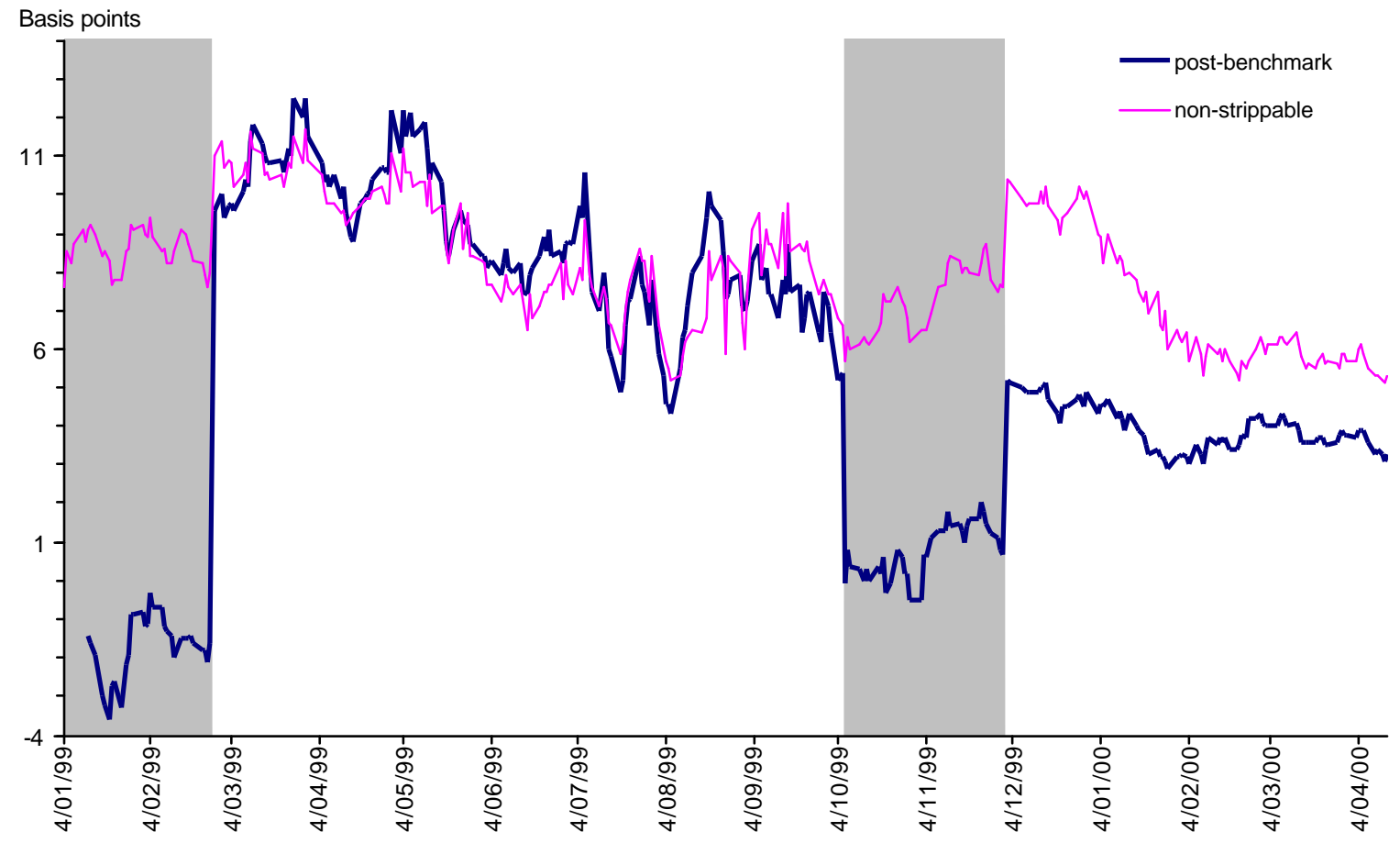

Zero-coupon yield curves are estimated using the Nelson-Siegel model until September 1999 and the Svensson model thereafter. Dummy variables are introduced to capture liquidity differences. The instantaneous forward rate of term $m$ is modelled in the following way for the Svensson model:

$\varphi_{m}=\beta_{0}+\beta_{1} e^{-\frac{m}{\tau_{1}}}+\beta_{2} \frac{m}{\tau_{1}} e^{-\frac{m}{\tau_{1}}}+\beta_{3} \frac{m}{\tau_{2}} e^{-\frac{m}{\tau_{2}}}+\gamma_{1}$ POSTBENCH $+\gamma_{2}$ NONSTRIP

This estimation corresponds to Model 3 . Shaded areas indicate that $\gamma_{1}$ is not statistically significant. 
Figure 5: Zero-coupon yield curve (Nelson-Siegel model, 29th March 1999)

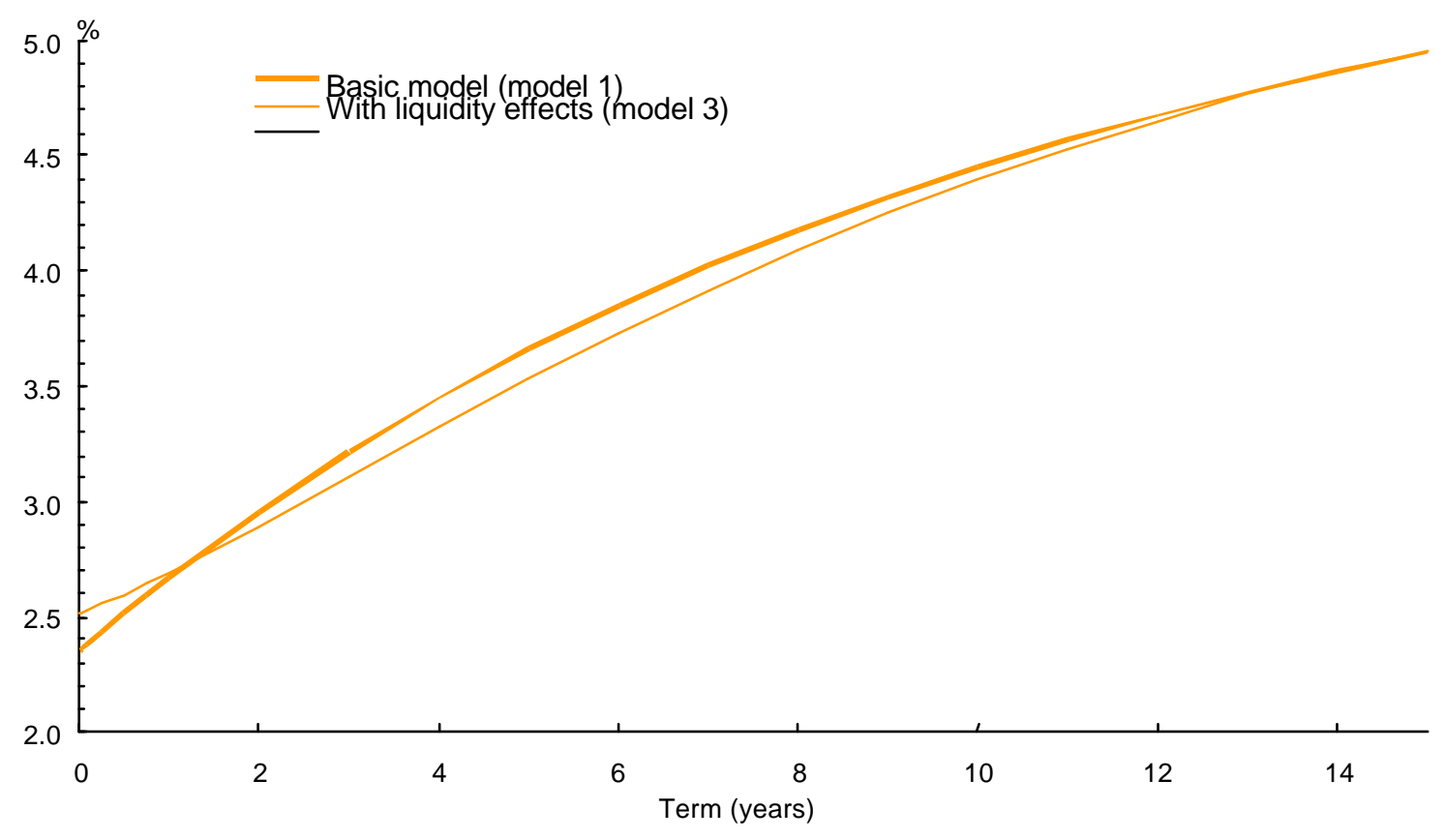

Figure 6: One-year forward curve (Nelson-Siegel model, 29th March 1999)

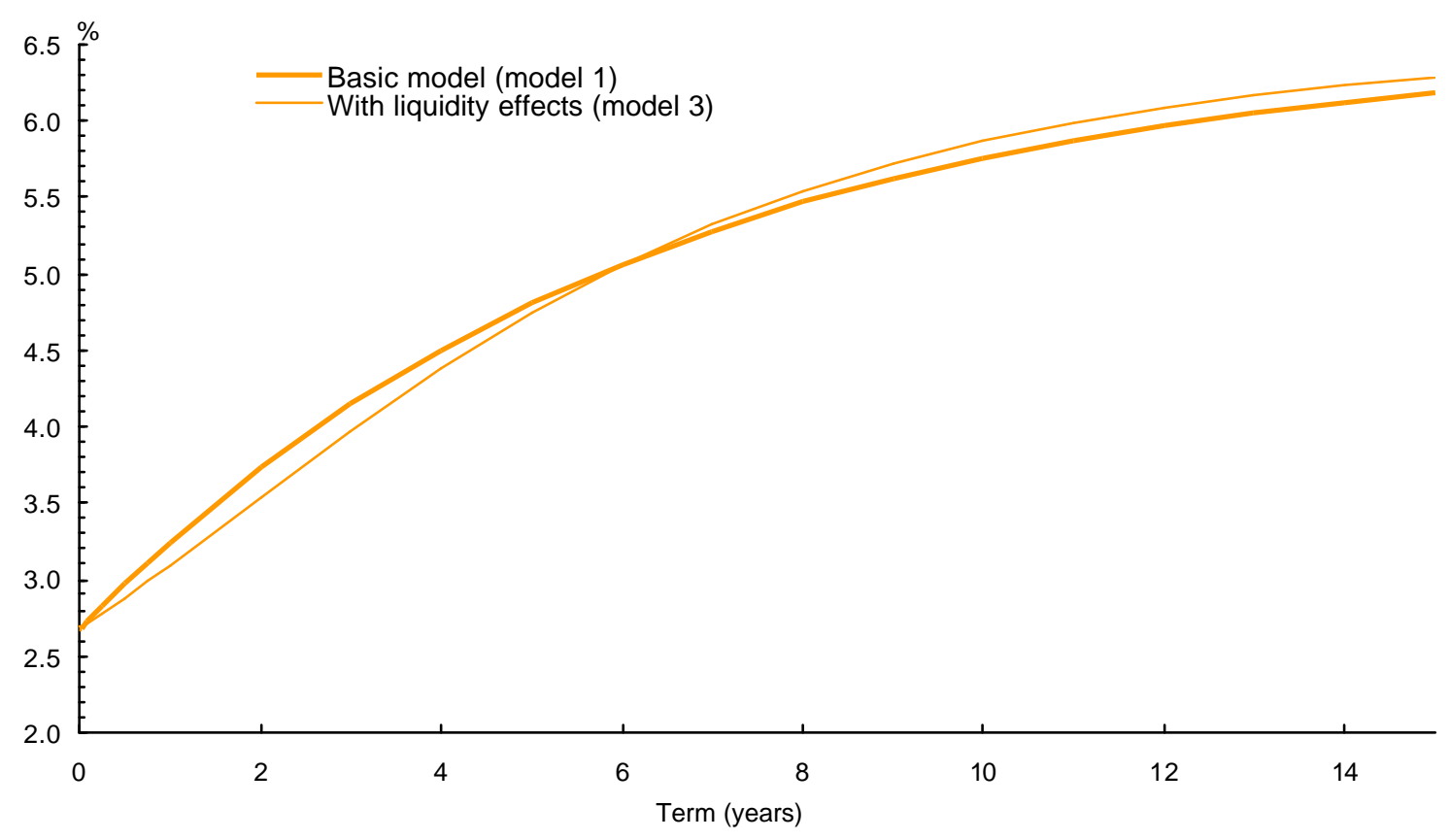


Figure 7: Zero-coupon yield curve (Svensson model, 31st March 2000)

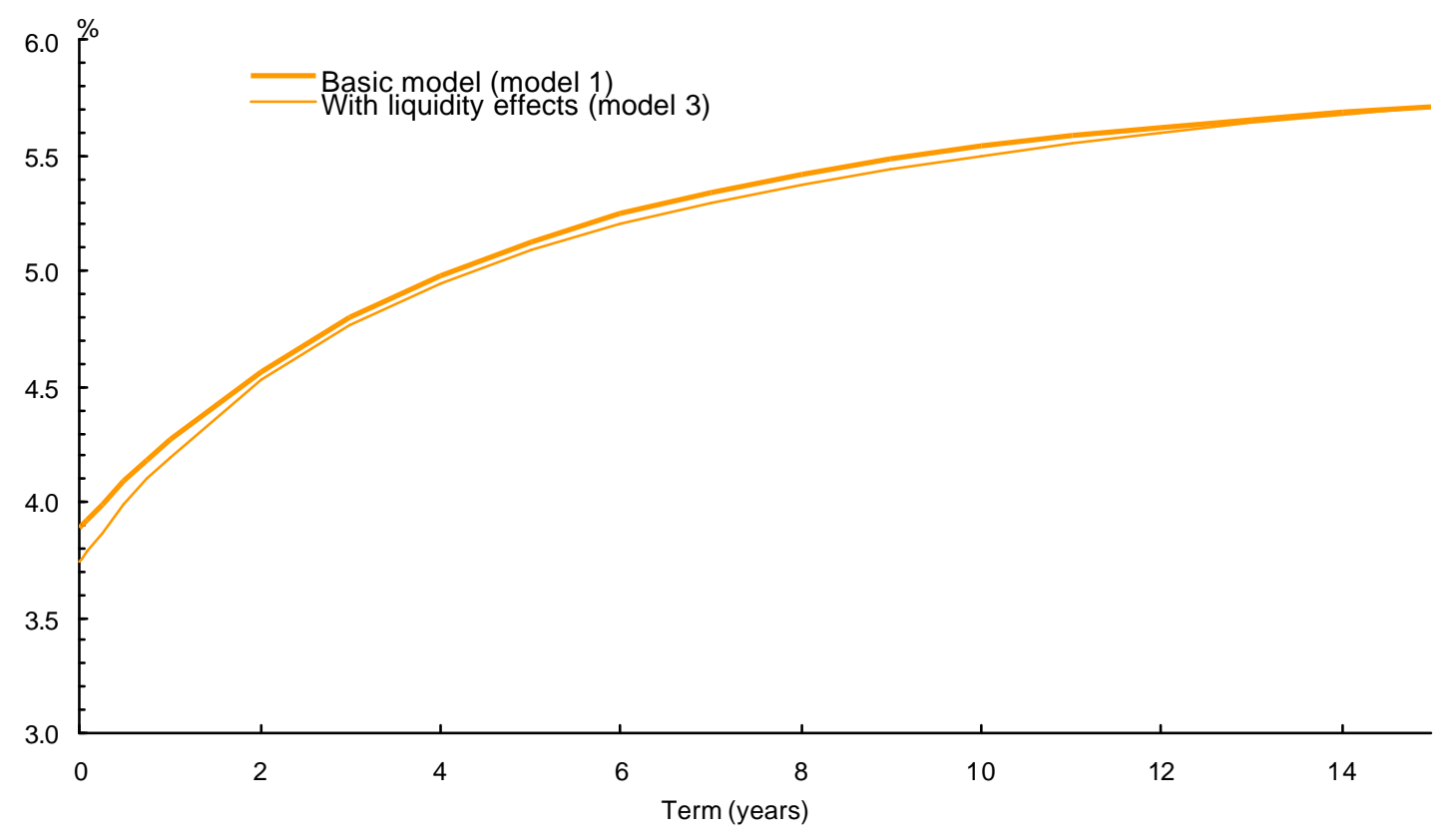

Figure 8: One-year forward curve (Svensson model, 31st March 2000)

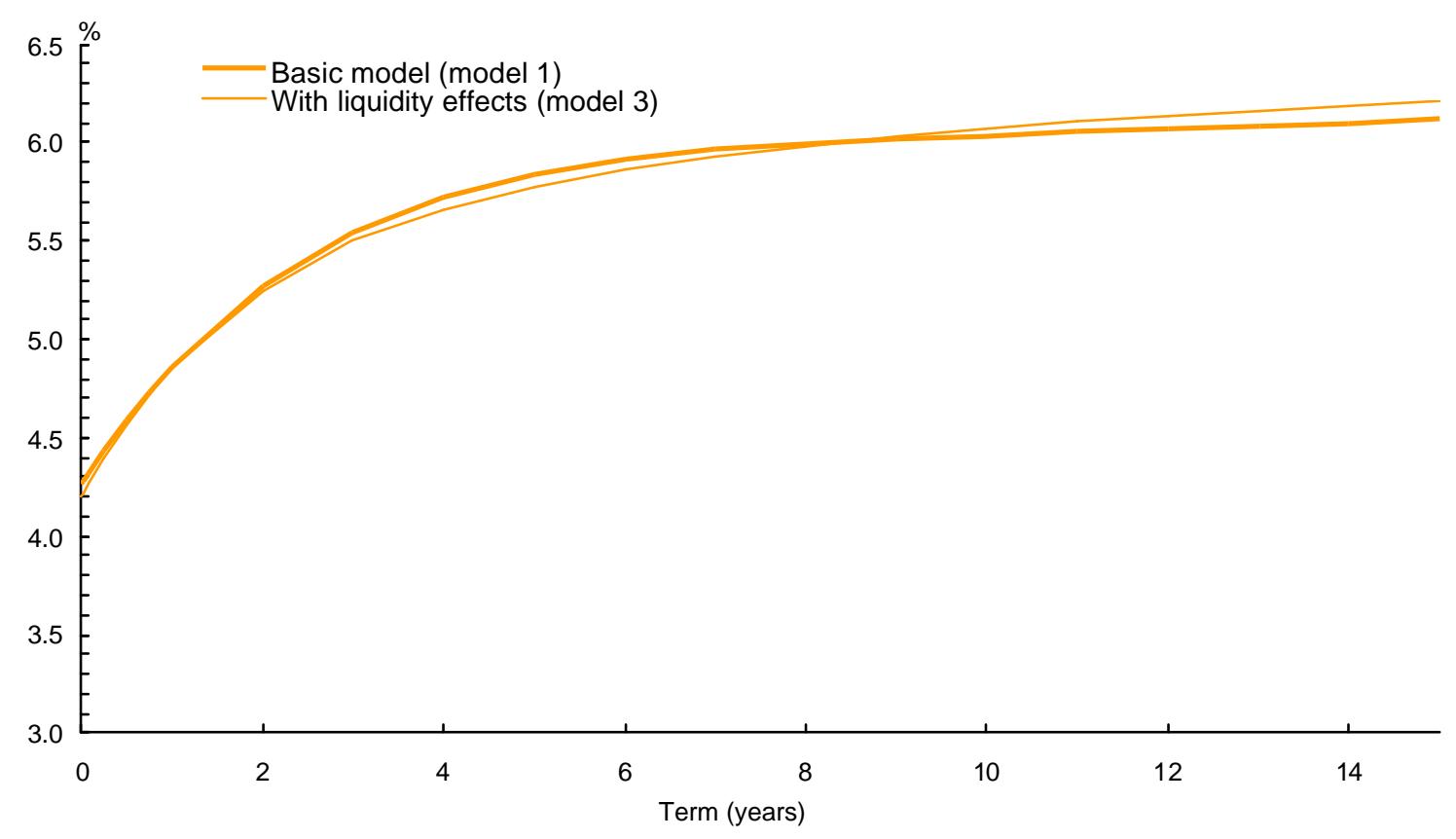

